\title{
COMPARAÇÃO DE INDICADORES DE DESENVOLVIMENTO: A APLICAÇÃO DO IDH E DO ISMA NA REGIÃO DO NORTE ARAGUAIA
}

COMPARISON OF THE DEVELOPMENT INDICATORS: THE APPLICATION OF THE

\author{
IDH AND ISMA IN NORTH ARAGUAIA
}

Antônio Augusto Barbosa Simão ${ }^{1}$

Armando Wilson Tafner Junior ${ }^{2}$

Alexandre Magno Melo de Faria ${ }^{3}$

\section{RESUMO}

A ideia de desenvolvimento sustentável é recente, surgindo no início dos anos 1960 porém ganhando força com a Comissão Mundial sobre o Meio Ambiente - CMMA conhecida como Comissão Brundtland $e$ com a realização da Rio 92. O presente trabalho tem como objetivo principal comparar os indicadores IDH e ISMA para avaliação dos municípios da Região Norte Araguaia. A pesquisa bibliográfica buscou primeiramente destacar os elementos teóricos de desenvolvimento sustentável e endógeno. Na sequência, fez-se a pesquisa histórica com resgate da colonização do Estado e da mesorregião Nordeste de Mato Grosso segundo recorte espacial do IMEA que no trabalho denominaremos de e Norte Araguaia em que o levantamento indica que os planos de ocupação e projetos de colonização deixarão externalidades ambientais negativas para a região e estado. Como terceira etapa tem-se a pesquisa descritiva quali-quantitativa, onde se consolida dados socioeconômicos e ambientais da região Norte Araguaia. E, por fim, a pesquisa buscou extrair os principais resultados aplicando o Índice de Desenvolvimento Humano IDH e Índice de Sustentabilidade dos Municípios da Amazônia - ISMA, onde os resultados obtidos da comparação do dois indicadores apontaram que devido a sua metodologia o IDH não é capaz de revelar o verdadeiro grau de desenvolvimento da região, já a análise do ISMA apontou para a existência de uma necessidade de ajustes nas políticas institucionais e econômicas para melhorar o desempenho de sustentabilidade, que segundo a metodologia do mesmo apontou que dezenove municípios da região classificaram-se com baixo desenvolvimento sustentável, dois médios e um com índice muito baixo de sustentabilidade.

Palavras chave: Desenvolvimento Sustentável, Sustentabilidade dos Municípios da Amazônia, Sustentabilidade, ISMA, IDH.

\footnotetext{
${ }^{1}$ Graduado em Economia pela Universidade Federal de Mato Grosso. E-mail: augustosimao.amna@gmail.com

${ }^{2}$ Graduado em Economia pela Universidade Estadual de Maringá (UEM). Mestre e Doutor em Desenvolvimento Socioambiental pelo Núcleo de Altos Estudos Amazônicos da Universidade Federal do Pará (NAEA/UFPA). Email: armandowilson@hotmail.com.

${ }^{3}$ Graduado em Economia Pela Universidade Federal de Mato Grosso (UFMT). Mestre e Doutor em Desenvolvimento Socioambiental pelo Núcleo de Altos Estudos Amazônicos da Universidade Federal do Pará (NAEA/UFPA). Professor da Universidade Federal de Mato Grosso (UFMT). E-mail:dr.melofaria@gmail.com
} 


\begin{abstract}
The idea of sustainable development is recent, emerging in the early 1960s but gaining strength with the World Commission on Environment - CMMA known as the Brundtland Commission and the holding of Rio 92. This study aims to compare the HDI indicators ISMA and to assess the municipalities of North Araguaia region. The bibliographic research aimed primarily highlight the theoretical elements of sustainable and endogenous development. Following, there was historical research to rescue the colonization of the state and meso Northeast of Mato Grosso second spatial area of IMEA that the work shall call and Northern Araguaia where the survey indicates that the plans of occupation and colonization projects fail negative environmental externalities to the region and state. As a third step there is the descriptive qualitative and quantitative, which consolidates socioeconomic and environmental data from the North Araguaia region. And finally, the research sought to extract the main results of applying the Human Development Index HDI and Sustainability Index of Amazon Municipalities - ISMA, where the results comparing the two indicators showed that due to its methodology the HDI is not able to reveal the true level of development of the region, since the analysis of the ISMA pointed to the existence of a need for adjustments in institutional and economic policies to improve the sustainability performance, which according to the methodology of the same pointed out that nineteen municipalities in the region classified with low sustainable development, two medium and one with very low level of sustainability.
\end{abstract}

Keywords: Sustainable Development, Sustainability of the Amazon municipalities, Sustainability, ISMA, HDI.

JEL: C43; L16

Introdução

A porção Nordeste do estado de Mato Grosso que é composta pelos biomas do Cerrado e Amazônia pertence a Bacia hidrográfica do Araguaia e que neste artigo será denominada de Norte Araguaia. Integram a esta região os 22 municípios sendo estes: Água Boa; Alto Boa Vista; Bom Jesus do Araguaia; Campinápolis; Canabrava do Norte; Canarana; Cocalinho; Confresa; Gaúcha do Norte; Luciara; Nova Nazaré; Nova Xavantina; Novo Santo Antônio; Porto Alegre do Norte; Querência; Ribeirão Cascalheira; Santa Cruz do Xingu; Santa Terezinha; São Félix do Araguaia; São José do Xingu; Serra Nova Dourada e Vila Rica. (IMEA, 2010, p.3).

Com uma área territorial total de $157.010 \mathrm{~km}^{2}$, abrigando aproximadamente $7 \%$ da população estadual, dos municípios que compõem a região, Nova Xavantina possui densidade demográfica maior que a do estado de Mato Grosso, a composição dos solos são na porção de Cerrado adequados para o cultivo de culturas perenes. A porção Leste da região é formada por savanas susceptíveis a inundação e propícias para a produção de bovinos. O restante da região 
é formado em sua maioria por florestas do bioma amazônico, onde a pecuária é a principal atividade econômica. "Apesar de a distância limitar o trânsito e a comercialização entre os dois principais polos econômicos da região, Vila Rica e Água Boa, o sistema produtivo da pecuária, que ainda é a principal atividade econômica da região, é muito semelhante em toda a sua extensão". (IMEA, 2010, p.3)

Anteriormente habitada por povos Xavante, Tapirapé, Karajá, entre outros povos indígenas a ocupação por colonização de população exógenas com ethos do capitalismo foi orientada pelo PIN (Programa de Integração Nacional) afim de integrar esta região de Mato Grosso a economia nacional, através de financiamentos de obras de infraestrutura logísticas, influenciando a colonização das margens da BR-158, porém o desenvolvimento no Norte Araguaia acabou se tornando alvo de um método de colonização onde interesse privados faziam-na afim de movimentação de capital. Influenciados por Programas como o PROTERRA que financiava compra de terras na Amazônia Legal. "Pequenos proprietários do Centro Sul tiveram acesso a financiamento para aquisição de diminutas porções de terras por meio de projetos de colonização particular ou cooperativas”. (RIBEIRO, 2013, P.23).

Esses colonos ao chegarem na região enfrentaram uma dura realidade, devido à crise que afligia o país já nos anos 1980 muitos dos projetos não tinham mais os financiamento de outrora nem contavam com a infraestrutura implementada nos primórdios do PIN, lançados a própria sorte e sem contar com um aporte do Governos e das Colonizadoras, muitos desses pequenos produtores vendem suas terras, alguns retornando ao seus Estados de origem, outros continuando a trabalhar nestas, mas agora como empregado. Essas características associadas a ao baixo nível tecnológico, riqueza e renda, privilegiaram o surgimento de grandes latifúndios, que devido à falta de uma política ambiental geraram enormes prejuízos ao meio ambiente da região. "Empobrecidos e com dívidas dos empréstimos, a maioria dos colonos desistiu do projeto, voltando para suas terras de origem ou tornando-se assalariados nas cidades e áreas próximas" (MELO, 2009, p.30).

Essa forma de produção latifundiária, é derivada de um modelo de desenvolvimento proposto pelos governo federal militar em meados da década de 60 , “que visava introduzir um modelo de desenvolvimento econômico na região amazônica, com base em obras de infraestrutura - como a abertura de rodovias - e em incentivos fiscais e créditos à iniciativa privada". (MELO, 2009, p.26). O Governo Estadual por meio da Companhia de Desenvolvimento do Estado de Mato Grosso CODEMAT, "viabilizou o processo de alienação dessas terras para a iniciativa privada". (RIBEIRO, 2013, p.114) 
Com base nestas informações e devido a necessidade de se mensurar o prejuízos causado por este tipo de ocupação será usada a ferramenta ISMA (Índice de Sustentabilidade dos Municípios da Amazônia), cuja metodologia de avalição é composta por quatro dimensões (político-institucional, econômico, ambiental e sociocultural), cada uma com seus indicadores e variáveis. A metodologia desta ferramenta surge da necessidade de se medir o nível de sustentabilidade dos municípios da Amazônia Legal (FARIA, 2013, p.3), visto que o Índice de Desenvolvimento Humano (IDH) embora muito utilizado, e que também será analisado neste trabalho, apresenta na formulação de seu cálculo uso de médias o que torna difícil a percepção de disparidade entre diferentes grupos analisados, além de não contemplar neste cálculo as dimensões ecológicas, humanas, cultural e política.

A partir das considerações elencadas o objetivo deste trabalho é comparar os dois indicadores para avaliação dos municípios da Região Norte Araguaia, estimar e apontar os maiores desvios no índice, para que este possa servir como parâmetro norteador na melhoria do processo de tomada de decisões dos gestores públicos a partir das demandas atuais e futuras da sociedade.

\section{DESENVOLVIMENTO?}

Partindo de uma ideia clássica, herdada no século XIX, onde o crescimento econômico por si só já assegurava o desenvolvimento, este termo passou ao longo do tempo a associar a sua conceituação preocupação com o social, cultural e político, ou seja, essa definição deve ser de crescimento econômico com externalidades sociais e ambientais positivas, é preciso ter “em mente que o crescimento continua sendo condição necessária ao desenvolvimento, apesar de não ser, de modo algum, suficiente" (SACHS, 1986, p. 98).

A teoria do desenvolvimento considera, em linhas gerais, que o mesmo está relacionado à utilização, execução e valorização de recursos locais e à capacidade de controle do processo de acumulação, possibilitando a geração de rendimentos crescentes, por meio do uso de recursos disponíveis e da introdução de inovações, garantindo criação de riqueza e melhoria do bem-estar. A implantação de monoculturas como a soja e a pecuária na Amazônia vem se expandindo de maneira acelerada nos últimos anos, pois grande parte de seu superávit na balança de exportações nacional, advém de tais commodities. Entretanto, tal avanço parece representar um risco ambiental, uma vez que sua expansão da Fronteira Agropecuária, tornou-a uma das principais causas de desmatamento na região. (RIBEIRO, 2013, P.62) 
A expansão da fronteira agrícola no Norte Araguaia, ocorreu num primeiro momento baseando-se nos modelos exógenos, onde o desenvolvimento firmou-se através de políticas de oferta de condições e incentivos diretos para o desenvolvimento da região, com implantação de infraestrutura rodoviária, juros baixos, incentivos tributários, programas de modernização tecnológica, aquisição de equipamentos, que culminou com a mobilização e vinda de grande contingente humano principalmente da região Sul e Sudeste afim de ocupar a região. "As vantagens oferecidas pelo Governo, somado ao preço baixo das terras, e as riquezas minerais, madeireiras e a possibilidade de valorização futura das terras, foram motivos suficientes para despertar o interesse dos empresários" (BARROZO, 1992, p.8)

Porém associados a especulação imobiliária e obtenção de créditos facilitados pela SUDAM, a expansão da fronteira agrícola no Norte Araguaia gerou a formação de grandes latifúndios que pouco acrescentaram ao desenvolvimento da região, visto que muito se degradou da paisagens naturais e o retorno dos investimentos ficaram concentrado nas mãos dos capitalistas que exploravam a terra. "O controle do capital pertencente a uma minoria provoca a exploração de uma maioria devido à busca pelo lucro, proporcionando assim, um desenvolvimento excludente" (TAFNER JR, 2015, p.64).

Amaral Filho destaca ainda que "não há receita pronta para esse tipo de desenvolvimento" (AMARAL FILHO, 2001, p. 278). "Como bem disse Celso Furtado num dos seus derradeiros pronunciamentos, só haverá verdadeiro desenvolvimento - que não se deve confundir com crescimento econômico, no demais das vezes resultado de mera modernização das elites - ali onde existir um projeto social subjacente" (SACHS, 2005, p. 9).

\subsection{Desenvolvimento Sustentável}

Uma das definições mais difundidas diz que o "desenvolvimento sustentável é aquele que atende as necessidades do presente sem comprometer as possibilidades de as gerações futuras atenderem suas próprias necessidades” (CMMAD,1991, p. 46). Segundo Romeiro (2001, p. 7-8), o termo "surgiu num contexto de controvérsia sobre as relações entre crescimento econômico e meio ambiente, exacerbada principalmente pela publicação do relatório do Clube de Roma que pregava o crescimento zero como forma de evitar a catástrofe ambiental".

Ribeiro (2002, p.42) considera que "o conceito de desenvolvimento sustentável é provavelmente o mais amplo, complexo e difundido já criado pela humanidade". O caminho 
intermediário é frequentemente identificado com o desenvolvimento sustentável, que se fundamenta em três pilares igualmente importantes: "relevância social, prudência ecológica e viabilidade econômica" (SACHS, 2002, p. 35). E ideal de sustentabilidade "corresponde às necessidade estratégicas delineadas por manifestações concretas de insustentabilidade", devendo essa sim ser descrita e compreendida para averiguar seus mecanismos e combatê-los.

O desenvolvimento sustentável não diz respeito apenas ao impacto do crescimento econômico em degradação ao meio ambiente, para Nascimento (2008, p. 21) o desenvolvimento sustentável "requer: um sistema político que assegure a efetiva participação dos cidadãos no processo decisório; um sistema econômico capaz de gerar excedentes e know how técnico em bases confiáveis e constantes; um sistema social que possa resolver as tensões causadas por um desenvolvimento não equilibrado; um sistema de produção que preserve a base ecológica do desenvolvimento; um sistema internacional que estimule padrões sustentáveis de comércio e financiamento; e um sistema administrativo flexível e capaz de se autocorrigir".

Veiga (2005 p.85) afirma que o conceito de desenvolvimento sustentável é um sonho a ser alcançado, defendendo ainda que o desenvolvimento deve ser caracterizado por mudanças qualitativas relacionadas à forma como as pessoas vivem e como as estruturas produtivas e institucionais funcionam. "O processo de desenvolvimento pode expandir as capacidades humanas, expandindo as escolhas que as pessoas têm para viver vidas plenas e criativas. E as pessoas são tanto beneficiárias desse desenvolvimento, como agentes do processo e da mudança que provocam."

O meio ambiente é, assim, a interação do conjunto de elementos naturais, artificiais e culturais que propiciem o desenvolvimento equilibrado da vida em todas as suas formas. A integração busca assumir uma concepção unitária do ambiente compreensiva dos recursos naturais e culturais (SILVA, 1995, p. 2). Além disso, é preciso encontrar um caminho intermediário "entre o fundamentalismo ecológico e o economicismo arrogante" (SACHS, 2002, p. 52).

\subsection{Desenvolvimento Endógeno}

A corrente que aborda o Desenvolvimento Endógeno surge entre os anos de 1980 e 1990 em que o cenário global vive um momento de incertezas, globalização da economia e novas formas mais flexíveis de acumulação, onde os autores desta corrente defendem que o 
desenvolvimento deve atender as necessidades e demandas da população através da participação da comunidade permitindo que esta possa liderá-lo. Para (BARQUERO, 2001, p.39) o principal objetivo do desenvolvimento endógeno é buscar o bem estar econômico, social e cultural da região envolvida.

Segundo o mesmo autor, os processos de crescimento e mudança estrutural resultam das estratégias e decisões de investimento das organizações que operam os mercados e estão integradas a esses condicionante da dinâmica econômica que são os entornos institucionais e culturais. (BARQUERO, 2001, p.38).

Para Amaral Filho (2001) "o desenvolvimento econômico ocorre em consequência da utilização do potencial e do excedente gerado localmente". Diz ainda que "para neutralizar as tendências ao estado estacionário, é preciso ativar os fatores determinantes dos processos de acumulação de capital, a saber, a criação e difusão de inovações no sistema produtivo, a organização flexível da produção, a geração de economias de aglomeração e de economias de diversidade nas cidades e o fortalecimento das instituições".

Sob seu ponto de vista o Desenvolvimento Endógeno, pode ser entendido como um processo no qual o crescimento econômico induz a uma contínua ampliação da capacidade de geração e agregação de valor sobre a produção e também da capacidade de absorção da região na retenção do excedente econômico gerado na economia local e na atração de excedentes provenientes de outras regiões. Nesse sentido, alguns componentes como redes, inovação, instituições e espaço são importantes como fonte de rendimentos crescentes (AMARAL FILHO, 2001).

Se a primeira tentativa de integrar a Região Norte Araguaia, usando-se de um modelo exógeno para atrair investimentos se mostrou bastante falha, cabe agora aos atores sociais e institucionais a criação de estratégias baseadas no modelo endógeno afim de promover a recuperação da região priorizando inclusão social e a solidariedade, visto que os fundamentos do modelo endógeno são os que melhor promovem a capacidade de recuperação da região onde é aplicada.

\section{MATO GROSSO: PROGRAMAS DE INTEGRAÇÃo E A OCUPAÇÃo DO NORTE ARAGUAIA}

O estado de Mato Grosso e toda a região Centro Oeste possuem uma história de ocupação antiga, porém, que se torna intensa apenas após década de 1930, onde foram 
realizadas pelo governo federal militar um conjunto de ações interligadas e complementares, com a finalidade de desbravar uma área do Brasil pouco conhecida e isolada do contexto nacional. Parte dessas ações englobavam estudos, decisões estratégicas, formulação de planos e programas, bem como o acompanhamento e controle de sua execução. Isto se deu pelo programa denominado "A marcha para o Oeste", de Getúlio Vargas (1937-1945), fixou brasileiros (não ameríndios) nesse território, através de assentamentos em pequenas propriedades rurais, dotados de certa infraestrutura, cujo objetivo era a absorção de excedentes populacionais do Sul e Sudeste do Brasil. (ISA, 2003, p.5)

À frente deste planejamento ficou a Fundação Brasil Central, cujo principal trabalho dos Irmãos Vilas Boas foi de mapear a região e contatar grupos indígenas que vivessem nas proximidades onde seriam instalados os núcleos. Em Mato Grosso, a fundação atuou ativamente na região do Norte Araguaia, e também no município de Barra do Garças. Com a forte atuação da FBC surgem diversos núcleos urbanos, destacando-se a cidade de Nova Xavantina (ALVES Jr, 2003). O trabalho dos Irmãos Villas Boas foi ainda responsável pela criação do Parque Indígena do Xingu no ano de 1964.

O governo Juscelino Kubitschek (1956-61) é marcado com a construção de Brasília (que passa a ser Capital Federal no Distrito Federal), no Estado de Goiás e os investimentos em infraestrutura na região Centro-Oeste, decorrentes do Plano de Metas, levaria a uma maior integração econômica, especialmente ao Estado de Goiás com a região Leste de Mato Grosso (OLIVEIRA et al, 2011, p.57).

Contribuindo para o crescimento econômico, durante o Governo JK é construída a BR-070, que se inicia em Brasília (DF) e termina no município de Cáceres-MT, na fronteira com a Bolívia. Contribuiu para que Goiânia se consolidasse como área de influência socioeconômica sobre o Leste mato-grossense, região de Barra do Garças (PINTO, 2006 p. 170).

Durante os governos militares entre 1964 a 1985 o estado de Mato Grosso, por pertencer a Amazônia Legal passa a se beneficiar das políticas e ações da então recém criada SUDAM - Superintendência do Desenvolvimento da Amazônia e da SUDECO Superintendência do Desenvolvimento do Centro-Oeste "ambas com o objetivo central, de coordenar e concentrar a ação governamental de planejamento e implantação de infraestrutura socioeconômica e institucional nas regiões Norte e Centro-Oeste, respectivamente" (OLIVEIRA et al, 2011, p.57).

Segundo Oliveira et al (2011 p.57) durante o governo Médici foi criado o Plano de 
Integração Nacional (PIN), cujo lema era "integrar para não entregar" criando um sentimento nacionalista, esse plano previa que cem quilômetros de ambos os lados das estradas que estavam sendo construídas seriam utilizadas para colonização esperava-se que mais de cem mil famílias fosses assentadas nestas áreas. $\mathrm{O}$ "PIN tinha como objetivos financiar obras de infraestrutura como: construir estradas e viabilizar a colonização às suas margens; integração das áreas amazônicas e nordestinas à nacional”.

Para dar suporte ao PIN é criado o Instituto Nacional de Colonização e da Reforma Agrária (INCRA), em 1970, sendo responsável pela criação e demarcação dos espaços vazios de colonização e assentamentos, visto que de cada lado das margens das rodovias federais no estado foram incorporadas ao patrimônio da União tornando estas áreas suscetíveis diretamente aos seus programas de colonização (OLIVEIRA et al, 2011, p.58). O INCRA contava ainda com incentivos diretos da SUDAM para estes projetos de colonização.

O Instituto de Terras do Estado de Mato Grosso (INTERMAT), é criado no ano de 1975 em substituição a CODEMAT, com objetivo de planejar e executar as políticas agrária e fundiária do Estado, a identificar as áreas devolutas e incorporá-las ao patrimônio do estadual e a regularizar as já ocupadas de maneira a eliminar conflitos sociais provocados pelo uso e posse de terra (OLIVEIRA et al, 2011, p.58).

O INCRA e a SUDAM passam a ter papel de planejadores e financiadores do desenvolvimento agropecuário na região, quando nessa mesma época, acontece a divisão territorial e administrativa do Estado de Mato Grosso, fazendo assim ainda mais importante a presença destes órgãos nas regiões de abertura do atual Estado de Mato Grosso, o Governo Federal dá início a construção das BR-158 e BR-163 junto com os Programas POLOAMAZÔNIA, o POLOCENTRO e POLONOROESTE para a abertura do Estado, conforme figura 1, outro importante programa para o Estado foi o PROTERRA que oferecia crédito para compra de terras na Amazônia Legal para a colonizadoras privada, fundamentais para a criação das cidades de Lucas do Rio Verde, Sinop e Sorriso ao Norte e ao Leste do Estado responsáveis pelos projetos que culminaram com a criação de Água Boa e Canarana e Vila Rica (OLIVEIRA et al, 2011, p.58)

A partir de 1977, apesar dos esforços do governo federal, os objetivos de integrar o Centro-Oeste e Amazônia a economia nacional ao longo das décadas de 1960 a 1980, começam a enfrentar grandes dificuldades como a concentração de propriedade, riqueza e renda, baixo nível tecnológico, não conhecimento das potencialidades, e dos poucos investimentos em infraestruturas, além dos conflitos ao longo da fronteira criada ao longo da 
BR-158 com as populações não indígenas que habitavam aquele território composta principalmente de castanheiros e seringueiros, expulsos dessas áreas durante processo de concentração das terras (BRITO, 2004).

A partir dos anos 1980 com a grave crise fiscal vivida pelo país, são adotadas pelo Estado uma política neoliberal conduzindo para uma nova forma de relação entre os agentes da produção, onde grandes empresas do agronegócio assumem os circuitos espaciais produtivos. E é durante o governo Collor nos anos 1990 que a região Centro Oeste fica órfã do seu órgão planejador de desenvolvimento, a SUDECO, ficando assim ao encargo do INCRA o papel de transformação dos territórios de fronteiras.

Em dias atuais, três planos estratégicos de desenvolvimento socioeconômico ambiental contemplam o Estado de Mato Grosso: o Plano Amazônia Sustentável (PAS), o Plano Estratégico de Desenvolvimento Sustentável do Centro-Oeste 2007-2020 (PDCO) e o Programa de Aceleração do Crescimento (PAC) onde o Estado deixa de ter a função de integrar por completo as ações de desenvolvimento da fronteira, assumindo uma função norteadora e em conjunto com a parceria privada (OLIVEIRA, 2011, p.59).

Toda essa forma de ocupação ocorreu primeiramente baseando-se num modelo de ocupação exógeno, que trouxe poucos ganhos qualitativos a ocupação desta fronteira agrícola, visto que esta ocorreu de forma desordenada, à custa de grande degradação ambiental, onde o desenvolvimento social não acompanhou o desenvolvimento econômico, restando ao Estado de Mato Grosso solucionar as marcas deixadas por este processo de expansão.

\subsection{A MESOREGIÃO NORTE ARAGUAIA}

A mesorregião Norte Araguaia possui área territorial total de $157.010 \mathrm{~km}^{2}$, integra 22 municípios do Estado e representa aproximadamente $7 \%$ da população estadual. Todos os municípios com exceção de Confresa e Nova Xavantina possuem densidade demográfica bem abaixo da densidade do Estado de Mato Grosso de 3,36 habitantes por quilômetros quadrados, fruto de um processo produtivo fortemente mecanizado ou de especialização agropecuarista que gerou na região essas enormes áreas de agricultura ou pastagem (IMEA, 2010, p.3). 


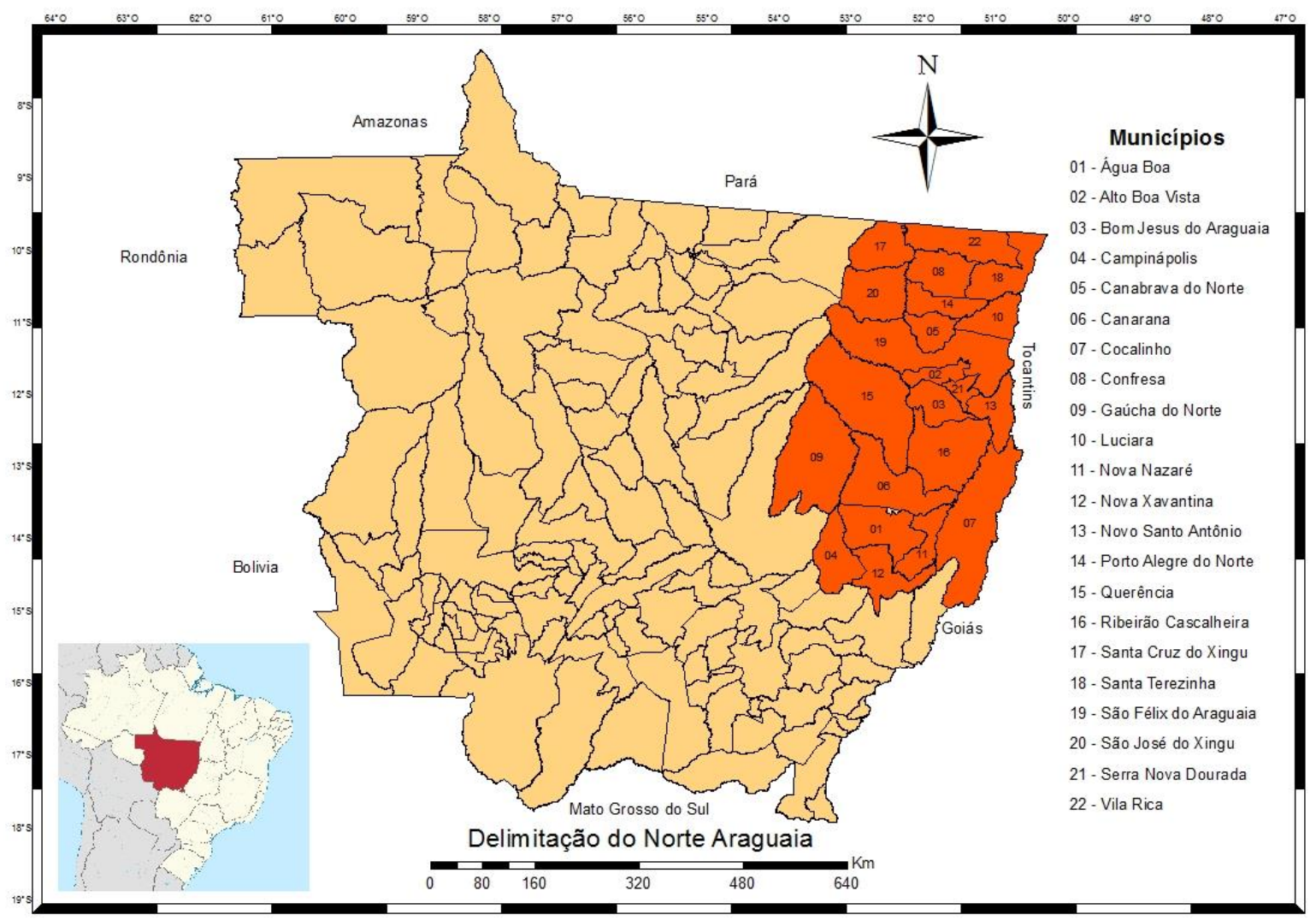

Figura 1 Mapa de delineamento da região Norte Araguaia .

Fonte: SEPLAN MT, IMEA, elaborado pelo autor.

A região apresenta um grande potencial para a produção da soja que vem experimentando expressivas taxas de crescimento da produção chegando em 2013 com 1.123 .796 (ton), representando aproximadamente $14 \%$ da produção do estado de Mato Grosso. Outras culturas que se destacam na região são a produção de feijão, mandioca, frutas, leite e seus derivados que fomentam principalmente a pequena agricultura familiar. A região apresenta ainda produção extensiva para a pecuária de corte, cria e recria, possuindo grande quantidade de frigoríficos instalados na região.

Confirmando os saldos positivos do estado em se manter entre os maiores produtores de grãos do pais, segundo as projeções do IMEA (2010) para a região Norte Araguaia, a produção da soja em grãos deverá passar de 3.746.669 toneladas em 2014 para aproximadamente 7.943 .842 toneladas em 2022, variação de aproximadamente $112 \%$. Este crescimento exigirá um esforço decorrente da ampliação em infraestrutura, investimento em pesquisa e ampliação na oferta energética, incorporando novas áreas em substituição a outras lavouras e a pecuária. Destaca-se também a projeção de produção do milho que deverá passar 
de 1.731.222 toneladas para 3.927.788 toneladas, uma variação de aproximadamente $127 \%$ na produção.

A região possui uma vocação para o turismo. O Rio Araguaia e o Rio Xingu são os limites naturais do Norte Araguaia e tornam a região um dos pontos turísticos de Mato Grosso com belas praias de areia branca e águas calmas e cristalinas, porém poucos exploradas. A expansão do turismo contemplativo, rural e ecológico seriam uma opção para o desenvolvimento econômico sustentável da região (SEDTUR, 2013).

A infraestrutura no estado de Mato Grosso, em especial na região Norte Araguaia, está passando por um período de mudanças. Porém a região carece de fortes investimentos em logística. Para se ir de Sinop a Confresa dois importantes centros urbanos do estado e que estão separadas em linha reta por uma distância igual ou menor que 400 quilômetros, só existe um caminho e este passa por Cuiabá, a MT-322 também conhecida como BR-080 encontra-se não concluída funcionando de forma muito precária, cortando o Parque Nacional do Xingu, sem contar que a travessia do Rio Xingu é feita por balsa administrada pelos índios do Posto de Vigilância que margeia esta estrada dentro do Parque (BRASIL, 2001, p.5).

Tal cenário chama atenção pois a separação desta porção do Estado e a facilidade de uso da BR-158 que liga a região a Barra do Garças levaram a região a se voltar mais para o estado do Goiás do que para Mato Grosso adotando inclusive o fuso horário do estado vizinho. O bom desempenho produtivo da região e o rápido crescimento do comércio internacional, e principalmente das importações, geram uma enorme demanda por infraestrutura logística (BRASIL, 2001, p.5).

Essas barreiras culturais, sociais e econômicas, o fracasso de projetos de colonização, haja visto que o insucesso destes projetos "deixaram de herança pra região grandes áreas devastadas e poucas oportunidades de acessão econômica a essa população" (BRASIL, 2001, p.6), levando a um afastamento progressivo e continuado da região com a capital matogrossense, tomando como anseio daqueles que habitam a região do Araguaia um sentimento de pró-emancipação desses municípios, culminando com a divisão territorial do Estado de Mato Grosso.

De tão forte sentimento de desprendimento da região com o restante do Estado os que ali habitam passaram a denomina-la de "Vale dos Esquecidos", esse desprendimento fez com que por algumas vezes fossem analisados, embora sem sucesso, no Congresso Nacional e Senado projetos de Lei que comtemplavam a criação de um novo Estado o Araguaia. Com o intuito de mudar essa mentalidade e ganhar autonomia, os prefeitos dos municípios da região, 
devido as suas similaridades econômicas, distanciamento da capital mato-grossense ocasionado por uma logística incompleta, esses administradores uniram-se na criação de uma associação que tem como missão dar a região mais notoriedade e força na busca de políticas públicas para o desenvolvimento do Norte Araguaia.

\subsection{CARACTERÍSTICAS SOCIOECONÔMICAS}

O grande desafio das nações nas últimas décadas têm sido a promoção do crescimento econômico ao mesmo tempo em que se reduz a desigualdade social. Com relação ao Índice Desenvolvimento Humano, utilizado para medir o grau de desenvolvimento econômico e a qualidade de vida oferecida à população, o quadro 1 demonstra que poucos são os municípios pertencentes à mesorregião Norte Araguaia com desempenho melhor ou semelhante ao do estado de Mato Grosso, quando o enfoque passa para a sustentabilidade é necessário fazer o uso de um indicador que se destaque como ferramenta de diagnóstico e aqui o ISMA tem caráter relevante devido a sua abrangência por considerar o relacionamento e comparação das dimensões chaves deste novo padrão de desenvolvimento sustentável.

As características sociais apresentadas evidenciam a importância do crescimento e desenvolvimento econômico como fator propulsor da melhoria da qualidade de vida da população local. A região possui municípios ainda muito novos em emancipação que carecem de melhores investimento e políticas públicas voltadas a aumentar a qualidade de vida da população. 


\begin{tabular}{|c|c|c|c|c|c|c|c|c|c|c|c|c|}
\hline & & \multicolumn{2}{|c|}{ PIB 2010 em mil R\$ } & \multicolumn{4}{|c|}{ IDH } & \multicolumn{5}{|c|}{ ISMA } \\
\hline & $\begin{array}{l}\text { População } \\
2010\end{array}$ & Total & $\begin{array}{l}\text { PIB per capita } \\
2010 \mathrm{R} \$\end{array}$ & Educação & Longevidade & Renda & IDH-M & $\begin{array}{l}\text { Politico } \\
\text { instit. }\end{array}$ & Econômica & Ambiental & $\begin{array}{l}\text { Socio- } \\
\text { cultural }\end{array}$ & ISMA \\
\hline Mato Grosso & 3035122 & 59599990000,00 & $19.636,77$ & 0,635 & 0,821 & 0,732 & 0,725 & 0,048 & 0,061 & 0,167 & 0,150 & 0,427 \\
\hline Água Boa & 20844 & $\mathrm{R} \$ 418.944,00$ & $\mathrm{R} \$ 20.099,02$ & 0,646 & 0,829 & 0,723 & 0,729 & 0,060 & 0,060 & 0,190 & 0,183 & 0,493 \\
\hline Alto Boa Vista & 5249 & $\mathrm{R} \$ 57.909,00$ & $\mathrm{R} \$ 11.032,39$ & 0,561 & 0,803 & 0,613 & 0,651 & 0,033 & 0,056 & 0,172 & 0,126 & 0,387 \\
\hline Bom Jesus do Araguaia & 5231 & $\mathrm{R} \$ 77.467,00$ & $\mathrm{R} \$ 14.809,21$ & 0,555 & 0,784 & 0,665 & 0,661 & 0,038 & 0,063 & 0,139 & 0,103 & 0,343 \\
\hline Campinápolis & 14305 & $\mathrm{R} \$ 125.784,00$ & $\mathrm{R} \$ 8.793,01$ & 0,324 & 0,803 & 0,597 & 0,538 & 0,050 & 0,063 & 0,171 & 0,094 & 0,378 \\
\hline Canabrava do Norte & 4767 & $\mathrm{R} \$ 75.029,00$ & $\mathrm{R} \$ 15.739,25$ & 0,589 & 0,817 & 0,616 & 0,667 & 0,029 & 0,053 & 0,155 & 0,118 & 0,355 \\
\hline Canarana & 18701 & $\mathrm{R} \$ 367.059,00$ & $\mathrm{R} \$ 19.627,77$ & 0,549 & 0,825 & 0,735 & 0,693 & 0,081 & 0,064 & 0,164 & 0,173 & 0,482 \\
\hline Cocalinho & 5498 & $\mathrm{R} \$ 101.833,00$ & $\mathrm{R} \$ 18.521,83$ & 0,528 & 0,807 & 0,674 & 0,660 & 0,032 & 0,049 & 0,174 & 0,123 & 0,378 \\
\hline Confresa & 25127 & $\mathrm{R} \$ 264.787,00$ & $\mathrm{R} \$ 10.537,95$ & 0,556 & 0,812 & 0,660 & 0,668 & 0,043 & 0,052 & 0,152 & 0,128 & 0,375 \\
\hline Gaúcha do Norte & 6287 & $\mathrm{R} \$ 100.126,00$ & $\mathrm{R} \$ 15.925,88$ & 0,418 & 0,847 & 0,658 & 0,615 & 0,043 & 0,075 & 0,155 & 0,163 & 0,436 \\
\hline Luciara & 2229 & $\mathrm{R} \$ 21.559,00$ & $\mathrm{R} \$ 9.672,05$ & 0,634 & 0,788 & 0,617 & 0,676 & 0,045 & 0,043 & 0,163 & 0,114 & 0,365 \\
\hline Nova Nazaré & 3021 & $\mathrm{R} \$ 31.248,00$ & $\mathrm{R} \$ 10.343,59$ & 0,427 & 0,793 & 0,621 & 0,595 & 0,065 & 0,044 & 0,168 & 0,111 & 0,388 \\
\hline Nova Xavantina & 19475 & $\mathrm{R} \$ 251.406,00$ & $\mathrm{R} \$ 12.909,17$ & 0,613 & 0,800 & 0,713 & 0,704 & 0,081 & 0,044 & 0,168 & 0,154 & 0,447 \\
\hline Novo Santo Antônio & 2005 & $\mathrm{R} \$ 22.935,00$ & $\mathrm{R} \$ 11.438,90$ & 0,526 & 0,829 & 0,640 & 0,653 & 0,037 & 0,039 & 0,132 & 0,128 & 0,336 \\
\hline Porto Alegre do Norte & 10754 & $\mathrm{R} \$ 99.351,00$ & $\mathrm{R} \$ 9.238,52$ & 0,587 & 0,803 & 0,647 & 0,673 & 0,039 & 0,054 & 0,170 & 0,127 & 0,390 \\
\hline Querência & 13021 & $\mathrm{R} \$ 398.717,00$ & $\mathrm{R} \$ 30.621,07$ & 0,565 & 0,837 & 0,701 & 0,692 & 0,055 & 0,065 & 0,141 & 0,184 & 0,445 \\
\hline Ribeirão Cascalheira & 8880 & $\mathrm{R} \$ 114.192,00$ & $\mathrm{R} \$ 12.859,46$ & 0,542 & 0,831 & 0,668 & 0,670 & 0,034 & 0,052 & 0,205 & 0,138 & 0,429 \\
\hline Santa Cruz do Xingu & 1899 & $\mathrm{R} \$ 36.665,00$ & $\mathrm{R} \$ 19.307,53$ & 0,550 & 0,828 & 0,704 & 0,684 & 0,016 & 0,076 & 0,171 & 0,138 & 0,401 \\
\hline Santa Terezinha & 7397 & $\mathrm{R} \$ 86.803,00$ & $\mathrm{R} \$ 11.734,89$ & 0,498 & 0,761 & 0,596 & 0,609 & 0,028 & 0,069 & 0,165 & 0,052 & 0,314 \\
\hline São Félix do Araguaia & 10531 & $\mathrm{R} \$ 160.290,00$ & $\mathrm{R} \$ 15.220,78$ & 0,538 & 0,848 & 0,652 & 0,668 & 0,052 & 0,073 & 0,119 & 0,182 & 0,426 \\
\hline São José do Xingu & 5267 & $\mathrm{R} \$ 108.796,00$ & $\mathrm{R} \$ 20.656,16$ & 0,487 & 0,828 & 0,703 & 0,657 & 0,035 & 0,054 & 0,161 & 0,112 & 0,362 \\
\hline Serra Nova Dourada & 1365 & $\mathrm{R} \$ 19.154,00$ & $\mathrm{R} \$ 14.032,23$ & 0,560 & 0,819 & 0,638 & 0,664 & 0,024 & 0,043 & 0,148 & 0,126 & 0,341 \\
\hline Vila Rica & 21403 & $\mathrm{R} \$ 291.374,00$ & $\mathrm{R} \$ 13.613,70$ & 0,553 & 0,829 & 0,709 & 0,688 & 0,062 & 0,051 & 0,137 & 0,165 & 0,415 \\
\hline
\end{tabular}

Quadro 1. Municípios região Norte Araguaia: população, PIB, IDH e ISMA.

Fonte: IBGE, PNUD, FARIA et al.2013a.

Revista de Estudos Sociais Ano 2016 N.36 V.18

Página 293 


\section{METODOLOGIA}

Os indicadores econômicos são utilizados para compreender e identificar problemas e auxiliares nas tomadas de decisões e soluções destes, a Agenda 21 Global documento apresentado durante a RIO92 fornece em seu capítulo 8, orientações de que os países deveriam desenvolver sistemas de monitoramento e avanço para o desenvolvimento sustentável, Segundo Bellen (2005, p.45), indicadores podem ser ferramentas de mudança, de aprendizado e de propaganda. Sua presença afeta o comportamento das pessoas. A sociedade mede o que valoriza e aprende a valorizar aquilo que mede. Essa retroalimentação é comum, inevitável e útil, mas também cheia de armadilhas.

\section{1 Índice de Desenvolvimento Humano - IDH}

Desenvolvido através do PNUMA com o objetivo de oferecer um contraponto a outro indicador muito utilizado, o Produto Interno Bruto (PIB) per capita, que leva em consideração apenas os vetores econômicos em sua medição, o IDH sugere que para mensurar o desenvolvimento da população devem ser levados em conta também características culturais, políticas e sociais relevantes para averiguar a evolução na qualidade de vida humana, os três pilares que constituem o IDH são mensurados da seguinte forma:

\section{Saúde}

Longevidade, uma vida longa e saudável é medida pela expectativa de vida, sugerindo que a longevidade está atrelada a uma adequada nutrição e sistema de saúde.

\section{Educação}

O acesso ao conhecimento é medido por capacidade de leitura e grau de alfabetização. O IDH utiliza em seus cálculos as variáveis:

- Alfabetização de adultos;

- Taxa de matricula combinada.

\section{Renda}

O padrão de vida leva em conta o Produto Interno Bruto dividido pela população, assim como também a Paridade do Poder de Compra PPC que tem a função de excluir as diferenças na valorização das moedas para efeito de comparação entre países.

O cálculo do IDH é resultado de uma média ponderada entre estas três dimensões (renda, longevidade e educação). O governo federal adota em seu Atlas de Desenvolvimento 
Humano do Brasil, o IDH-M, um ajuste metodológico do IDH Global, sua principal foca por levar em consideração o cálculo da renda municipal per capita, resultado de questionário mais detalhado colhido pelo IBGE durante o Censo Demográfico.

\begin{tabular}{|l|l|}
\hline \multicolumn{2}{|c|}{ Classificação do IDH } \\
\hline $0,800-1,000$ & Muito Alto \\
\hline $0,700-0,799$ & Alto \\
\hline $0,600-0,699$ & Médio \\
\hline $0,500-0,599$ & Baixo \\
\hline $0,000-0,499$ & Muito Baixo \\
\hline
\end{tabular}

Quadro 2 Classificação e Representação em níveis do IDH.

Fonte: PNUD - Atlas do Desenvolvimento Humano.

\section{2 Índice de Sustentabilidade dos Municípios da Amazônia - ISMA}

O Índice de Sustentabilidade dos Municípios da Amazônia foi desenvolvido a partir de 44 variáveis em 23 indicadores que estão agrupados em 9 subdimensões que possuem pesos diferenciados, sua distinção entre outros indicadores está associada à abrangência geográfica, será calculado para todos os municípios da Amazônia. O índice não só apresenta a realidade local como serve de norte e direcionamento de políticas públicas que busquem uma melhoria destes resultados (FARIA, et al 2013).

\subsubsection{Dimensão Político - Institucional}

Esta dimensão do Índice de Desenvolvimento dos Municípios da Amazônia trata da capacidade, participação e qualificação dos esforços governamentais nas ações necessárias para implementação do desenvolvimento sustentável, levando em conta existência de conselhos municipais paritários, pois assim pode se saber qual o nível de articulação da sociedade na democratização de políticas públicas. Ela se desdobra nas sub dimensões: Participação, Gestão Administrativa e Gestão Financeira listados no quadro (FARIA, 2013a). 


\begin{tabular}{|c|c|c|c|c|c|}
\hline Dimensão (peso) & $\begin{array}{c}\text { Subdimensão } \\
\text { (peso) }\end{array}$ & Indicadores & Peso & Variáveis & Peso \\
\hline \multirow{10}{*}{$\begin{array}{c}\text { DIMENSÃO } \\
\text { POLÍTICO - } \\
\text { INSTITUCION } \\
\text { AL }(0,25)\end{array}$} & \multirow{2}{*}{$\begin{array}{c}\text { Participação } \\
(0,4)\end{array}$} & $\begin{array}{l}\text { Capital } \\
\text { Social }\end{array}$ & 0,70 & $\begin{array}{l}\text { Existência de organizações } \\
\text { representativas da Sociedade } \\
\text { Civil }\end{array}$ & 1,00 \\
\hline & & Governança & 0,30 & $\begin{array}{l}\text { Existência de conselhos } \\
\text { municipais paritários }\end{array}$ & 1,00 \\
\hline & \multirow{2}{*}{$\begin{array}{c}\text { Gestão Adm. } \\
(0,3)\end{array}$} & \multirow{2}{*}{$\begin{array}{l}\text { Qualidade } \\
\text { do Quadro } \\
\text { Funcional }\end{array}$} & \multirow{2}{*}{1,00} & $\begin{array}{l}\text { Número de servidores por } \\
\text { mil habitantes }\end{array}$ & 0,50 \\
\hline & & & & $\begin{array}{l}\text { Percentual de servidores com } \\
\text { curso superior }\end{array}$ & 0,50 \\
\hline & \multirow{6}{*}{$\begin{array}{c}\text { Gestão } \\
\text { Financeira } \\
\qquad(0,3)\end{array}$} & \multirow{2}{*}{$\begin{array}{l}\text { Capacidade } \\
\text { de } \\
\text { arrecadação }\end{array}$} & \multirow{2}{*}{0,30} & $\begin{array}{l}\text { Receita Orçamentária per } \\
\text { capita }\end{array}$ & 0,50 \\
\hline & & & & $\begin{array}{l}\text { Percentual de Receita Própria } \\
\text { sobre a Receita Total }\end{array}$ & 0,50 \\
\hline & & \multirow{2}{*}{$\begin{array}{l}\text { Capacidade } \\
\text { de } \\
\text { Investimento }\end{array}$} & \multirow{2}{*}{0,35} & $\begin{array}{l}\text { Despesas com Investimentos } \\
\text { per capita }\end{array}$ & 0,50 \\
\hline & & & & $\begin{array}{l}\text { Despesas com Investimentos } \\
\text { sobre a Despesa Realizada }\end{array}$ & 0,50 \\
\hline & & \multirow[t]{2}{*}{$\begin{array}{l}\text { Saúde } \\
\text { financeira }\end{array}$} & \multirow[t]{2}{*}{0,35} & $\begin{array}{l}\text { \% da Receita Corrente } \\
\text { Líquida Comprometida com } \\
\text { Despesas de Pessoal }\end{array}$ & 0,50 \\
\hline & & & & Suficiência de Caixa & 0,50 \\
\hline
\end{tabular}

Quadro 3 Dimensão Político-Institucional, Subdimensões, Indicadores, Variáveis e Pesos.

Fonte: FARIA, et al 2013.

Dentro da Subdimensão Participação, o indicador capital social leva em consideração a quantidade de Organizações Representativas da Sociedade para cada mil habitantes, já para o indicador de existência de conselhos municipais paritários são levantados a presença de Conselhos de Educação, Saúde, Habitação, Saneamento, Direitos Humanos adotando uma resposta binária onde o sim é igual a 1 e não igual a zero. 
Na Subdimensão Gestão Administrativa o Indicador Qualidade do Quadro Funcional leva se em consideração duas Variáveis: número de servidores por mil habitantes e percentual de Servidores com nível superior.

Contando com três indicadores a subdimensão Gestão Financeira, que são coletados no site da Secretaria do Tesouro Nacional as informações referentes a Receita orçamentária, receita própria e receita total, a subdimensão leva em consideração seis variáveis.

No indicador Capacidade de Arrecadação, as variáveis analisadas são Receita Orçamentária per capita e percentual da Receita Própria sobre a Receita Total. Analisando a capacidade dos investimentos o ISMA leva em consideração as variáveis Despesas com Investimento per capita e Despesas com Investimentos sobre a Despesa Realizada.

Ainda em Gestão Financeira o Indicador de Saúde Financeira soma os dados das variáveis de percentual da receita corrente liquida comprometida com despesa de pessoal e suficiência de caixa.

\subsubsection{Dimensão Econômica}

A dimensão Econômica do ISMA leva em consideração o desempenho econômico local, os indicadores e variáveis que compõem esta dimensão elencados no quadro 4, mensuram e indicam o nível de pressão que o meio ambiente sofre com o crescimento destes, porém, o aumento destas variáveis também podem promover uma satisfação humana, diminuição do desemprego e combate à miséria (FARIA, 2013a).

O indicador Nível de Renda do ISMA leva em consideração no seu cálculo três variáveis, Remuneração dos empregos formais que é uma razão entra a soma do salários pelo número de empregado, o valor médio do rendimento mensal das pessoas com dez anos ou mais de idade e a renda per capita média dos mais pobres são as outras duas variantes que compõe esta dimensão, os dados são obtidos a partir do Censo Demográfico 2010 (FARIA et al, 2013a). 


\begin{tabular}{|c|c|c|c|c|c|}
\hline $\begin{array}{l}\text { Dimensão } \\
\text { (peso) }\end{array}$ & $\begin{array}{l}\text { Subdimensão } \\
\text { (peso) }\end{array}$ & Indicadores & Peso & Variáveis & Peso \\
\hline \multirow{8}{*}{$\begin{array}{c}\text { DIMENSÃO } \\
\text { ECONÔMIC } \\
\text { A }(\mathbf{0 , 2 5 )}\end{array}$} & \multirow{8}{*}{$\begin{array}{l}\text { Economia e } \\
\text { Renda }(1,0)\end{array}$} & \multirow{3}{*}{$\begin{array}{l}\text { Nível de } \\
\text { Renda }\end{array}$} & \multirow{3}{*}{0,35} & $\begin{array}{l}\text { Remuneração Média dos } \\
\text { Empregos Formais }\end{array}$ & 0,35 \\
\hline & & & & $\begin{array}{l}\text { Valor médio do rendimento } \\
\text { mensal das pessoas com } 10 \\
\text { anos ou mais de idade }\end{array}$ & 0,35 \\
\hline & & & & $\begin{array}{l}\text { Renda Per capita média dos } \\
\text { mais pobres }\end{array}$ & 0,30 \\
\hline & & \multirow{3}{*}{$\begin{array}{l}\text { Dinamismo } \\
\text { Econômico }\end{array}$} & \multirow{3}{*}{0,35} & $\begin{array}{l}\text { Evolução de Empregos } \\
\text { Formais }\end{array}$ & 0,35 \\
\hline & & & & $\begin{array}{l}\text { Média de Crescimento do PIB } \\
\text { no último triênio }\end{array}$ & 0,35 \\
\hline & & & & PIB per capita & 0,30 \\
\hline & & \multirow{2}{*}{$\begin{array}{c}\text { Arrecadação } \\
\text { Tributária }\end{array}$} & \multirow{2}{*}{0,30} & Receita de ICMS per capita & 0,50 \\
\hline & & & & Receita de ISS per capita & 0,50 \\
\hline
\end{tabular}

Quadro 4 Dimensão Econômica do ISMA, Subdimensões, Indicadores, Variáveis e Pesos.

Fonte: FARIA, et al 2013.

O Indicador de Dinamismo usa como variáveis para sua mensuração as variáveis da evolução dos empregos formais, média do crescimento do PIB e o PIB per capita.

Arrecadação Tributária é o terceiro indicador que compõe esta subdimensão ela resulta das variáveis receita de ICMS per capita e receita ISS per capita sua função é avaliar a eficácia dos municípios em arrecadação.

\subsubsection{Dimensão Ambiental}

A Dimensão Ambiental do ISMA leva em conta indicadores relacionados aos saneamento básico, preservação ambiental e gestão ambiental. Dentro do saneamento básico é importante analisar o percentual da coleta de lixo, pois este está ligado diretamente à saúde da população e também a proteção do meio ambiente, tanto que estes resíduos não coletados favorecem o proliferação de doenças, além de contaminar os solos e a água. O acesso a água 
tratada também é um indicador universal de desenvolvimento sustentável pois o acesso a esta é essencial a saúde e higiene (FARIA et al, 2013a).

\begin{tabular}{|c|c|c|c|c|c|}
\hline $\begin{array}{c}\text { Dimensão } \\
\text { (peso) }\end{array}$ & $\begin{array}{l}\text { Subdimensão } \\
\text { (peso) }\end{array}$ & Indicadores & Peso & Variáveis & Peso \\
\hline \multirow{7}{*}{$\begin{array}{c}\text { DIMENSÃO } \\
\text { AMBIENTAL } \\
(\mathbf{0 , 2 5 )}\end{array}$} & \multirow{7}{*}{$\begin{array}{c}\text { Meio } \\
\text { Ambiente } \\
\qquad(1,0)\end{array}$} & \multirow{3}{*}{$\begin{array}{c}\text { Saneamento } \\
\text { Básico }\end{array}$} & \multirow{3}{*}{0,30} & $\begin{array}{l}\text { Percentual de domicílios atendidos direta } \\
\text { ou indiretamente por coleta de lixo } \\
\text { domiciliar. }\end{array}$ & 0,30 \\
\hline & & & & $\begin{array}{l}\text { Percentual de domicílios com acesso a rede } \\
\text { geral de esgoto ou fossa séptica }\end{array}$ & 0,35 \\
\hline & & & & $\begin{array}{l}\text { Percentual de domicílios atendidos por rede } \\
\text { pública de água }\end{array}$ & 0,35 \\
\hline & & \multirow{2}{*}{$\begin{array}{c}\text { Preservação } \\
\text { Ambiental }\end{array}$} & \multirow[t]{2}{*}{0,50} & $\begin{array}{l}\text { Área desmatada no mun. em relação à área } \\
\text { total desmatada no estado no mesmo } \\
\text { período. }\end{array}$ & 0,40 \\
\hline & & & & $\begin{array}{l}\text { Expansão do desmatamento no último } \\
\text { triênio }\end{array}$ & 0,60 \\
\hline & & \multirow{2}{*}{$\begin{array}{c}\text { Gestão } \\
\text { Ambiental }\end{array}$} & \multirow{2}{*}{0,20} & $\begin{array}{l}\text { Efetividade da Estrutura de Gestão } \\
\text { Ambiental }\end{array}$ & 0,50 \\
\hline & & & & $\begin{array}{l}\text { Efetividade do Conselho Municipal de } \\
\text { Meio Ambiente }\end{array}$ & 0,50 \\
\hline
\end{tabular}

Quadro 5 Dimensão Ambiental do ISMA, Subdimensões, Indicadores, Variáveis e Pesos. Fonte: FARIA, et al 2013.

\subsubsection{Dimensão Sociocultural}

Esta dimensão do ISMA consiste de dados que levam em consideração objetivos ligados as necessidades básicas como saúde, educação, habitação e cultura. As variáveis elencadas no quadro 6 são fundamentais para a formulação de políticas públicas nas sub dimensões mencionadas, permitindo o dimensionamento de demandas de acesso pela população a estes serviços (FARIA et al, 2013). 


\begin{tabular}{|c|c|c|c|c|c|}
\hline $\begin{array}{l}\text { Dimensão } \\
\text { (peso) }\end{array}$ & $\begin{array}{l}\text { Subdimensão } \\
\quad \text { (peso) }\end{array}$ & Indicadores & Peso & Variáveis & Peso \\
\hline \multirow{11}{*}{$\begin{array}{c}\text { DIMENSÃO } \\
\text { SOCIO } \\
\text { CULTURAL } \\
(0,25)\end{array}$} & \multirow[b]{2}{*}{ Saúde $(0,3)$} & Longevidade & 0,50 & Índice de Esperança de vida ao nascer & 1,00 \\
\hline & & $\begin{array}{l}\text { Mortalidade } \\
\text { Infantil }\end{array}$ & 0,50 & Mortalidade Infantil & 1,00 \\
\hline & \multirow{4}{*}{$\begin{array}{c}\text { Educação } \\
(0,3)\end{array}$} & Escolaridade & 0,50 & $\begin{array}{l}\text { Pessoas de } 15 \text { anos ou mais que não } \\
\text { sabem ler e escrever (taxa de } \\
\text { analfabetismo) }\end{array}$ & 1,00 \\
\hline & & \multirow{3}{*}{$\begin{array}{l}\text { Qualidade do } \\
\text { Ensino }\end{array}$} & \multirow{3}{*}{0,50} & $\begin{array}{l}\text { Índice de Aproveitamento do Ensino } \\
\text { Básico - IDEB }\end{array}$ & 0,30 \\
\hline & & & & $\begin{array}{l}\text { Percentual de abandono escolar de } 6^{\mathrm{a}} \text { a } 9^{\mathrm{a}} \\
\text { série }\end{array}$ & 0,35 \\
\hline & & & & $\begin{array}{l}\text { Percentual de abandono escolar no ensino } \\
\text { médio }\end{array}$ & 0,35 \\
\hline & \multirow{4}{*}{$\begin{array}{l}\text { Habitação } \\
(0,2)\end{array}$} & \multirow{4}{*}{$\begin{array}{l}\text { Estrutura de } \\
\text { Gestão para } \\
\text { políticas } \\
\text { habitacionais }\end{array}$} & \multirow{4}{*}{1,00} & $\begin{array}{l}\text { Existência de Plano Municipal de } \\
\text { Habitação (pronto ou em elaboração) }\end{array}$ & 0,25 \\
\hline & & & & $\begin{array}{l}\text { Existência de Conselho Municipal de } \\
\text { Habitação }\end{array}$ & 0,25 \\
\hline & & & & $\begin{array}{l}\text { Existência de Fundo Municipal de } \\
\text { Habitação }\end{array}$ & 0,25 \\
\hline & & & & $\begin{array}{l}\text { Existência de Cadastro ou Levantamento } \\
\text { de famílias interessadas em programas de } \\
\text { Hab. }\end{array}$ & 0,25 \\
\hline & Cultura $(0,2)$ & $\begin{array}{l}\text { Infraestrutura } \\
\text { cultural }\end{array}$ & 1,00 & $\begin{array}{l}\text { Existência de Equipamentos } \\
\text { Socioculturais }\end{array}$ & 1,00 \\
\hline
\end{tabular}

Quadro 6 Dimensão Sócio Cultural do ISMA, Subdimensões, Indicadores, Variáveis e Pesos.

Fonte: FARIA, et al 2013.

A subdimensão saúde agrega duas variáveis, Longevidade e Mortalidade Infantil, contribuem por avaliar a disponibilidade e o acesso aos serviços de saúde, o aumento da longevidade está relacionada as melhores condições de saúde assim como a redução da mortalidade são objetivos importantes para o desenvolvimento sustentável (FARIA et al, 2013a). 
A subdimensão educação possui 4 variáveis distribuídas em dois indicadores, escolaridade e qualidade do ensino essas variáveis em conjunto evidenciam algumas características do acesso da população ao sistema educacional.

Dentro da subdimensão Habitação o indicador Estrutura de Gestão das Políticas Habitacionais conta com quatro variáveis que avaliam se há participação dos entes envolvidos, dos conselhos, se há um fundo para a criação de novas moradias e interesse da população. A Subdimensão cultura leva em consideração a existência de equipamentos socioculturais nos municípios hora avaliados.

Pelo fato dos indicadores selecionados para cada dimensão serem mensurados em diferentes unidades de medida e com diferentes amplitudes de variação, eles são transformados em medidas adimensionais com magnitude entre 0 e 1 .

A representação matemática do ISMA (FARIA et al 2014) apresenta-se a seguir:

Passo 1 - Cálculo do Indicador

$$
I=\sum p * V
$$

Onde

I= Indicador

$\mathrm{p}=$ Peso associado às variáveis

$\mathrm{V}=$ Variáveis;

Passo 2 - Cálculo da Subdimensão SD

$S D=\sum I * p$

Onde,

$\mathrm{I}=$ Indicador

$\mathrm{SD}=$ Subdimensão

$\mathrm{p}=$ Peso do Indicador na Subdimensão

Passo 3 - Cálculo da Dimensão

$D=\sum S D * p$

Onde,

$\mathrm{D}=$ Dimensão

$\mathrm{SD}=$ Subdimensão

$\mathrm{p}=$ Peso da Subdimensão na Dimensão 
Passo 4 - Cálculo Índice

$I S M A=\sum D$

Onde,

$\mathrm{D}=$ Dimensão

Importante destacar, que variados são os métodos para obter os pesos de cada indicador, sendo alguns puramente estatísticos, outros uma mescla de conveniências e critérios subjetivos e estatísticos. Em princípio, a escolha dos limites e dos pesos depende da utilização específica que se deseja dar ao Índice (FARIA et al, 2014).

\begin{tabular}{|l|l|}
\hline \multicolumn{2}{|c|}{ Classificação do ISMA } \\
\hline Menor que 0,329 & Muito Baixo \\
\hline Entre 0,330 e & \\
0,477 & Baixo \\
\hline De 0,478 até & \\
0,602 & Médio \\
\hline De 0,603 & Alto \\
\hline
\end{tabular}

\section{Quadro 7 Classificação e representação dos índices em níveis do ISMA}

Fonte: FARIA, et al 2013a

Quanto a classificação do ISMA, os valores menores que 0,329 revelam a existência de um estado muito baixo de sustentabilidade, os índices com valores entre 0,330 e 0,477 são representados por um performance que revela baixo e também e uma situação de alerta para estes municípios, os índices entre 0,478 a 0,602 apontam para uma situação de performance aceitável de sustentabilidade, já para os índices com uma valoração acima de 0,603 revelam uma situação alta de sustentabilidade. (FARIA et al, 2013a).

Com o propósito de Classificação da Região Norte Araguaia se fará a classificação dos municípios segundo o IDH-M e o ISMA, este último será comparado entre os municípios e o estado de Mato Grosso.

\section{RESULTADOS}

\subsection{O IDH no Norte Araguaia}


A proposta deste capitulo é fazer uma análise do desempenho do Índice de Desenvolvimento Humano Municipal - IDH-M, as dimensões são as mesmas do IDH, porém, alguns dos indicadores usados são diferentes, para melhor avaliar as condições de núcleos sociais menores. Com os dados do IDH-M da Região Norte Araguaia, é possível fazer uma análise descritiva dos mesmo. O quadro 8 apresenta os resultados dos 22 municípios da região Norte Araguaia e do estado de Mato Grosso em cada um dos componentes Educação, Longevidade, Renda e IDH-M.

\begin{tabular}{|c|c|c|c|c|}
\hline \multirow{2}{*}{ UF / Município } & \multicolumn{4}{|c|}{ IDH - 2010} \\
\hline & Educação & Saúde & Renda & IDHM \\
\hline Mato Grosso & 0,635 & 0,821 & 0,732 & 0,725 \\
\hline Água Boa & 0,646 & 0,829 & 0,723 & 0,729 \\
\hline Alto Boa Vista & 0,561 & 0,803 & 0,613 & 0,651 \\
\hline Bom Jesus do Araguaia & 0,555 & 0,784 & 0,665 & 0,661 \\
\hline Campinápolis & 0,324 & 0,803 & 0,597 & 0,538 \\
\hline Canabrava do Norte & 0,589 & 0,817 & 0,616 & 0,667 \\
\hline Canarana & 0,549 & 0,825 & 0,735 & 0,693 \\
\hline Cocalinho & 0,528 & 0,807 & 0,674 & 0,660 \\
\hline Confresa & 0,556 & 0,812 & 0,660 & 0,668 \\
\hline Gaúcha do Norte & 0,418 & 0,847 & 0,658 & 0,615 \\
\hline Luciara & 0,634 & 0,788 & 0,617 & 0,676 \\
\hline Nova Nazaré & 0,427 & 0,793 & 0,621 & 0,595 \\
\hline Nova Xavantina & 0,613 & 0,800 & 0,713 & 0,704 \\
\hline Novo Santo Antonio & 0,526 & 0,829 & 0,640 & 0,653 \\
\hline Porto Alegre do Norte & 0,587 & 0,803 & 0,647 & 0,673 \\
\hline Querência & 0,565 & 0,837 & 0,701 & 0,692 \\
\hline Ribeirão Cascalheira & 0,542 & 0,831 & 0,668 & 0,670 \\
\hline Santa Cruz do Xingu & 0,550 & 0,828 & 0,704 & 0,684 \\
\hline Santa Terezinha & 0,498 & 0,761 & 0,596 & 0,609 \\
\hline São Félix do Araguaia & 0,538 & 0,848 & 0,652 & 0,668 \\
\hline São José do Xingu & 0,487 & 0,828 & 0,703 & 0,657 \\
\hline Serra Nova Dourada & 0,560 & 0,819 & 0,638 & 0,664 \\
\hline Vila Rica & 0,553 & 0,829 & 0,709 & 0,688 \\
\hline
\end{tabular}




\section{Quadro 8 IDH - M Região Norte Araguaia e Estado de Mato Grosso.}

Fonte: PNUD.

No quadro 8, a dimensão IDH-M Educação foi a que apresentou os piores resultados para a região, três municípios: Água Boa, Luciara e Nova Xavantina obtiveram índices semelhantes ao do estado de Mato Grosso, o que os classificam com um índice médio de desenvolvimento; os municípios de Campinápolis, Gaúcha do Norte, Nova Nazaré, Santa Terezinha e São José do Xingu apresentaram índices considerados muito baixo, ademais os outros 14 municípios que compõem a região apresentaram um baixo resultado do desempenho da educação.

Considerando a dimensão do Longevidade do IDH-M no quadro 8, com exceção de Santa Terezinha, Nova Nazaré, Luciara e Bom Jesus do Araguaia que obtiveram um índice alto, todos conseguiram um valor muito alto no desempenho do índice que mede a longevidade do IDH-M.

A dimensão renda do IDH-M foi a que apresentou maior diversidade nos dados. Os municípios de Campinápolis e Santa Terezinha conseguiras índices que os classificam com baixo desempenho no quesito renda, treze municípios tiveram um resultado mediano e os melhores colocados foram Água Boa, Canarana, Nova Xavantina, Querência, Santa Cruz do Xingu, São José do Xingu e Vila Rica que apresentaram um resultado que os classificam com um alto desempenho neste indicador.

O valor médio do IDH-M da Região Norte Araguaia encontra-se na faixa, em que o IDH-M é considerado médio (entre 0,500 e 0,799). Dois municípios apresentaram IDH-M considerado baixo (abaixo de 0,500), são eles Nova Nazaré com 0,595 e Campinápolis com 0,538, os municípios de Água Boa e Canarana encontram-se na faixa de IDH-M considerado alta (entre 0,700 e 0,799).

Um ponto negativo a ser observado no IDH é que por este ser resultado de uma média das três dimensões três municípios foram classificados como médios mesmo tendo resultados muito baixo em educação, apenas pela influência de uma classificação de muito alta no indicador de saúde (longevidade).

Por não abrigar em sua metodologia outras variáveis que mensuram a qualidade de vida da população, perguntas ficam no ar. O IDH é eficaz em apontar os pontos negativos do desenvolvimento? Seria o IDH capaz de revelar o grau de desenvolvimento da comunidade? “O PNUD admite que o IDH é um ponto de partida. Recorda que o processo de 
desenvolvimento é muito mais amplo e mais complexo do que qualquer medida sumária conseguiria captar, mesmo quando completada com outros índices” (VEIGA, 2005, p. 87).

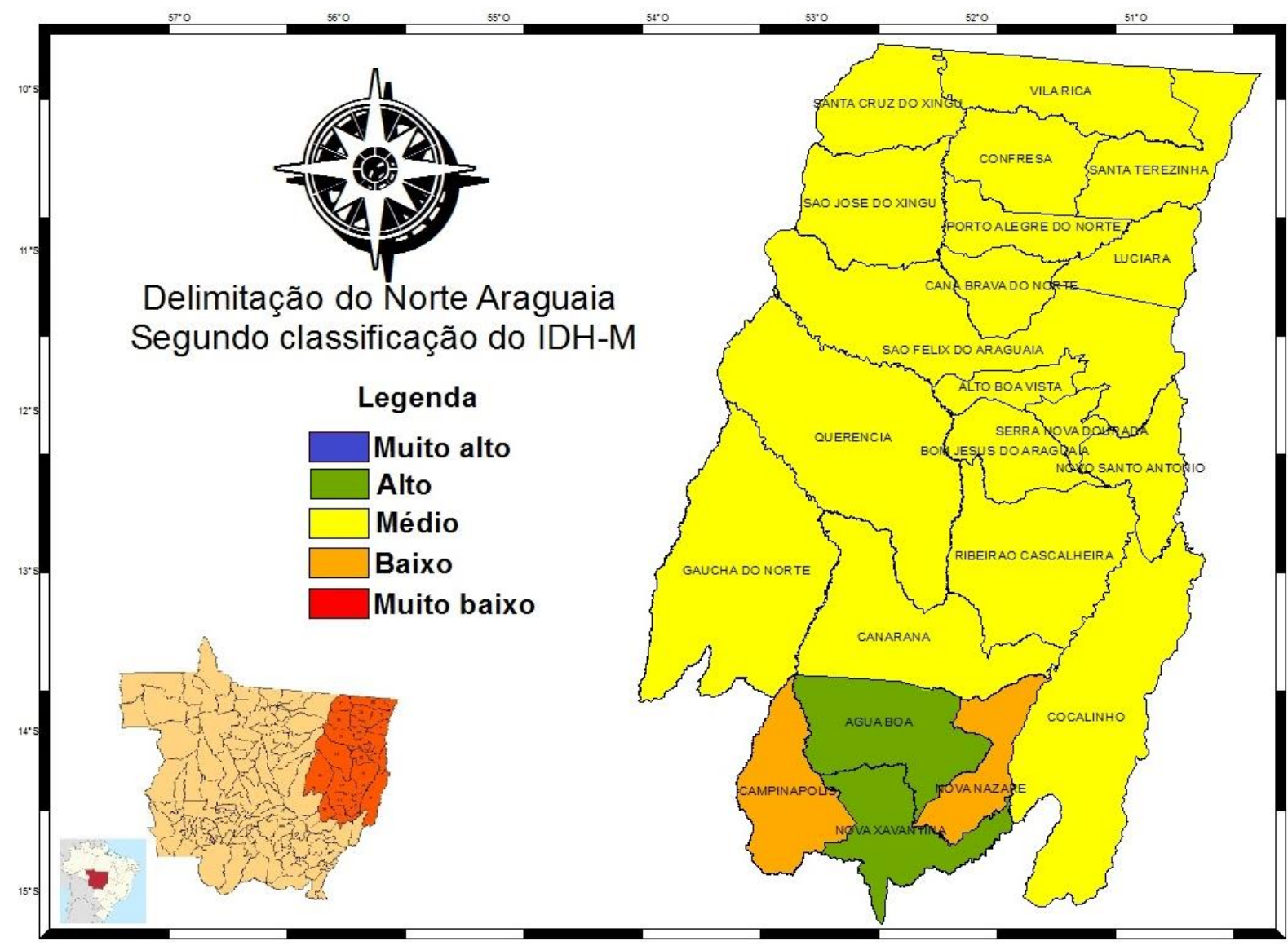

Figura 2 Delimitação da Região Norte Araguaia segundo a Classificação do IDH-M

Fonte: PNUD, SEPLAN - MT, elaborado pelo autor.

Mesmo sendo uma importante ferramenta de avaliação do desenvolvimento humano o IDH não apresenta uma solução adequada para a Região Norte Araguaia. A figura 2 apresenta a delimitação da Região Norte Araguaia classificação dos municípios dentro do IDH-M, uma singularidade que se percebe é que os municípios que estão classificados como alto e baixo são vizinhos, Nova Nazaré que fora desmembrada de Água Boa ao ganhar status de município em 1999 e Campinápolis de Nova Xavantina em 2005.

\subsection{O Norte Araguaia e o ISMA Político - Institucional}

A dimensão Político-Institucional do ISMA contempla o uso de dez variáveis organizadas em seis indicadores alocados em três subdimensões, aqui são avaliados a participação das organizações, sociedade e a gestão dos recursos públicos. "A estrutura 
institucional deve contribuir para a integração dos fatores econômicos, ambientais e sociais de forma harmônica. Esse é um aspecto do desenvolvimento sustentável capaz de ser alcançado somente pela qualidade das instituições da sociedade. Portanto, é essencial a participação da sociedade nos processos decisórios, em conselhos ou associações e o aumento do nível educacional das pessoas ligadas a essas instituições."

O quadro 9 apresenta os resultados das variáveis da Dimensão Político-institucional do ISMA aplicado a região Norte Araguaia, na subdimensão Participação são analisados no indicador Capital Social o número de Organização de representação da sociedade civil por mil habitantes e o Indicador de Governança que levam em conta a existência de Conselhos Municipais e deliberativos. Os municípios da região apresentaram um péssimo desempenho indicador, porém São José do Xingu, Santa Cruz do Xingu e Serra Nova Dourada obtiveram um resultado igual a zero, o que ainda denota pouca ou nenhuma participação da sociedade civil nas tomadas de decisões.

A Gestão Administrativa possui dois indicadores que avaliam a Qualidade do quadro funcional, que são quantidade de servidores pra cada mil habitantes e quantidade de servidores com nível superior, novamente os municípios apresentaram um resultado muito baixo dessa variável, porém os apresentaram um melhor resultado foram, Canarana 0,116, Nova Nazaré 0,115, São José do Xingu 0,098 e Bom Jesus do Araguaia 0,091. Figurando entre os últimos estão: Querência 0,02, Santa Terezinha 0,022, Canabrava do Norte 0,012 e Vila Rica 0,008 em qualidade do quadro funcional.

Capacidade de arrecadação, Capacidade de Investimento, Saúde financeira são os indicadores que compõe a terceira subdimensão Gestão Financeira da Política Institucional do ISMA, os municípios de Nova Xavantina 0,109, Vila Rica 0,094, Canarana 0,073 e Água Boa 0,067 por serem municípios mais velhos em emancipação conseguiram o melhor resultado na região, porém um resultado que ainda os mantem com um escore no ISMA que os qualifica com baixo desenvolvimento sustentável no indicador.

A somatória das três subdimensões temas com seus pesos atribuídos dão aos municípios de Nova Xavantina 0,081, Canarana 0,081, Nova Nazaré 0,065, Vila Rica 0,062, Água Boa 0,060, Querência 0,055 e Ribeirão Cascalheira com 0,054 um resultado na dimensão melhor que até mesmo o do estado de Mato Grosso com 0,048. 


\begin{tabular}{|c|c|c|c|c|c|c|c|c|c|c|c|c|}
\hline \multicolumn{13}{|c|}{ Dimensão Politico Institucional } \\
\hline \multirow[b]{2}{*}{ MUNICÍPIO } & \multicolumn{3}{|c|}{ Participação } & \multicolumn{2}{|c|}{ Gestão Administrativa } & \multicolumn{4}{|c|}{ Gestão Financeira } & \multirow{2}{*}{$\begin{array}{c}\text { valor do indice } \\
\text { de } \\
\text { sustentabilidade } \\
\text { Pol. Instit. } \\
\text { (soma das } \\
\text { subdimensões) }\end{array}$} & \multirow[b]{2}{*}{ Peso } & \multirow[b]{2}{*}{$\begin{array}{r}\text { Valor da } \\
\text { Dimensão }\end{array}$} \\
\hline & $\begin{array}{l}\text { Capital } \\
\text { Social }\end{array}$ & Governança & $\begin{array}{c}\text { Valor da } \\
\text { Subdimensão } \\
\text { Participação }\end{array}$ & $\begin{array}{l}\text { Qualidade do } \\
\text { Quadro } \\
\text { Funcional }\end{array}$ & $\begin{array}{c}\text { Valor da } \\
\text { Subdimensão } \\
\text { Gestão Adm. }\end{array}$ & $\begin{array}{c}\text { Capacidade } \\
\text { de } \\
\text { arrecadação }\end{array}$ & $\begin{array}{l}\text { Capacidade de } \\
\text { Investimento }\end{array}$ & $\begin{array}{c}\text { Saúde } \\
\text { financeira }\end{array}$ & $\begin{array}{c}\text { Valor da } \\
\text { Subdimensão } \\
\text { Gestão } \\
\text { Financeira }\end{array}$ & & & \\
\hline Água Boa & 0,027 & 0,300 & 0,131 & 0,142 & 0,043 & 0,077 & 0,08 & 0,07 & 0,067 & 0,240 & 0,25 & 0,060 \\
\hline Alto Boa Vista & 0,011 & 0,075 & 0,034 & 0,216 & 0,065 & 0,026 & 0,02 & 0,07 & 0,034 & 0,133 & 0,25 & 0,033 \\
\hline Bom Jesus do Araguaia & 0,011 & 0,000 & 0,004 & 0,305 & 0,091 & 0,085 & 0,03 & 0,07 & 0,055 & 0,151 & 0,25 & 0,038 \\
\hline Campinápolis & 0,043 & 0,225 & 0,107 & 0,139 & 0,042 & 0,018 & 0,08 & 0,07 & 0,051 & 0,200 & 0,25 & 0,050 \\
\hline Canabrava do Norte & 0,028 & 0,075 & 0,041 & 0,040 & 0,012 & 0,039 & 0,09 & 0,08 & 0,063 & 0,117 & 0,25 & 0,029 \\
\hline Canarana & 0,034 & 0,300 & 0,134 & 0,386 & 0,116 & 0,092 & 0,08 & 0,07 & 0,073 & 0,322 & 0,25 & 0,081 \\
\hline Cocalinho & 0,017 & 0,075 & 0,037 & 0,163 & 0,049 & 0,033 & 0,02 & 0,09 & 0,041 & 0,127 & 0,25 & 0,032 \\
\hline Confresa & 0,005 & 0,150 & 0,062 & 0,158 & 0,047 & 0,042 & 0,09 & 0,08 & 0,063 & 0,172 & 0,25 & 0,043 \\
\hline Gaúcha do Norte & 0,018 & 0,150 & 0,067 & 0,202 & 0,061 & 0,059 & 0,04 & 0,05 & 0,042 & 0,170 & 0,25 & 0,043 \\
\hline Luciára & 0,017 & 0,225 & 0,097 & 0,083 & 0,025 & 0,025 & 0,11 & 0,07 & 0,059 & 0,181 & 0,25 & 0,045 \\
\hline Nova Nazaré & 0,000 & 0,225 & 0,090 & 0,383 & 0,115 & 0,021 & 0,09 & 0,06 & 0,054 & 0,259 & 0,25 & 0,065 \\
\hline Nova Xavantina & 0,165 & 0,225 & 0,156 & 0,194 & 0,058 & 0,068 & 0,20 & 0,09 & 0,109 & 0,323 & 0,25 & 0,081 \\
\hline Novo Santo Antônio & 0,000 & 0,075 & 0,030 & 0,266 & 0,080 & 0,031 & 0,02 & 0,07 & 0,037 & 0,147 & 0,25 & 0,037 \\
\hline Porto Alegre do Norte & 0,069 & 0,000 & 0,028 & 0,265 & 0,079 & 0,055 & 0,04 & 0,07 & 0,050 & 0,157 & 0,25 & 0,039 \\
\hline Querência & 0,079 & 0,300 & 0,152 & 0,074 & 0,022 & 0,063 & 0,03 & 0,07 & 0,047 & 0,221 & 0,25 & 0,055 \\
\hline Ribeirão Cascalheira & 0,019 & 0,300 & 0,128 & 0,154 & 0,046 & 0,086 & 0,00 & 0,06 & 0,044 & 0,217 & 0,25 & 0,054 \\
\hline Santa Cruz do Xingu & 0,000 & 0,000 & 0,000 & 0,081 & 0,024 & 0,021 & 0,05 & 0,06 & 0,041 & 0,065 & 0,25 & 0,016 \\
\hline Santa Terezinha & 0,020 & 0,075 & 0,038 & 0,072 & 0,022 & 0,033 & 0,07 & 0,07 & 0,052 & 0,112 & 0,25 & 0,028 \\
\hline São Félix do Araguaia & 0,088 & 0,150 & 0,095 & 0,248 & 0,074 & 0,045 & 0,02 & 0,06 & 0,037 & 0,207 & 0,25 & 0,052 \\
\hline São José do Xingu & 0,000 & 0,000 & 0,000 & 0,325 & 0,098 & 0,017 & 0,01 & 0,07 & 0,031 & 0,129 & 0,25 & 0,032 \\
\hline Serra Nova Dourada & 0,000 & 0,000 & 0,000 & 0,199 & 0,060 & 0,016 & 0,03 & 0,07 & 0,035 & 0,095 & 0,25 & 0,024 \\
\hline Vila Rica & 0,065 & 0,300 & 0,146 & 0,026 & 0,008 & 0,065 & 0,13 & 0,12 & 0,094 & 0,247 & 0,25 & 0,062 \\
\hline
\end{tabular}

Quadro 9 Dimensão Político-Institucional do ISMA para os municípios do Norte Araguaia.

Fonte: FARIA, et al 2013.

Revista de Estudos Sociais Ano 2016 N.36 V.18 


\subsection{O Norte Araguaia e a Dimensão Econômica do ISMA}

A dimensão econômica do Índice de sustentabilidade dos municípios da Amazônia conta com três indicadores organizados em oito variáveis de receita dos municípios, evolução dos empregos, a distribuição da renda e produto interno bruto.

A análise do quadro 10 traz a Dimensão Econômica do ISMA para os municípios no Norte Araguaia, ilustrando o desempenho de nas três subdimensões Nível de Renda, Dinamismo Econômico e Arrecadação tributária.

A subdimensão Nível de Renda é formada pelas variáveis: Remuneração Média dos Empregos Formais, Valor médio rendimento Mensal das pessoas com 10 anos ou mais e Renda Per capita média dos mais pobres, esta variável por si só é insuficiente para expressar o bem-estar da população, porém quando agregadas estas outras variáveis pode mensurar melhor o ritmo de crescimento dos municípios, além de detalhar melhor a distribuição da renda, nesta subdimensão os municípios que apresentaram melhor resultado foram: Gaúcha do Norte 0,204, São Félix do Araguaia 0,192, Santa Terezinha 0,156 e Canarana com 0,150 e ocupando as últimas posições estão Nova Xavantina com um indicador de 0,066, São José do Xingu em 0,058, Novo Santo Antônio 0,045 e Luciara com 0,034.

Alguns municípios do Norte Araguaia vêm nos últimos quinze anos trocando sua tradição de produção pecuária intensiva pela agricultura que embora mecanizada tem um melhor aproveitamento mão de obra local e isto influi diretamente nesta subdimensão do indicador como pode ser visto pois os municípios que apresentaram os melhores resultados: Santa Cruz do Xingu com resultado de 0,157, São José do Xingu com 0,155, Bom Jesus do Araguaia 0,152 e Campinápolis com 0,133 são os que mais obtiveram mudanças, onde a evolução do emprego formal parece ter acompanhado o crescimento do PIB, já os municípios de Alto Boa Vista com 0,088, Confresa 0,084 e Ribeirão Cascalheira com 0,066 tiveram o pior resultado da Região.

A subdimensão tema Arrecadação Tributária é sem dúvida a que merece melhor atenção dos entes administradores na região seus indicadores Receita de ICMS per capita e Receita de ISS per capita apresentaram dados muito baixos. Os municípios com melhor resultado foram: Luciára com 0,011, São Félix do Araguaia 0,009, Porto Alegre do Norte 0,008 e Ribeirão Cascalheira com 0,007, dados preocupantes pois estas variáveis auxiliam na avaliação da capacidade do município de gerar receitas por meio do monitoramento 
permanente das variáveis que resultam no crescimento ou redução do repasse do ICMS e arrecadação dos ISSQN (Imposto Sobre Serviço de Qualquer Natureza). 


\begin{tabular}{|c|c|c|c|c|c|c|c|c|c|c|c|c|c|}
\hline \multicolumn{14}{|c|}{ DIMENSÃO ECONÔMICA } \\
\hline \multirow[b]{2}{*}{ MUNICÍPIO } & \multicolumn{4}{|c|}{ Nível de Renda } & \multicolumn{4}{|c|}{ Dinamismo Econômico } & \multicolumn{3}{|c|}{ Arrecadação Tributária } & \multirow[b]{2}{*}{$\begin{array}{c}\text { Valor da } \\
\text { Subdimensão } \\
\text { na } \\
\text { Dimensão }\end{array}$} & \multirow[b]{2}{*}{$\begin{array}{l}\text { VALOR DA } \\
\text { DIMENSÃO }\end{array}$} \\
\hline & \begin{tabular}{|c} 
Remuneraçã \\
o Média dos \\
Empregos \\
Formais
\end{tabular} & $\begin{array}{c}\text { Valor médio } \\
\text { rend. Mens. } \\
\text { pessoas com } \\
10 \text { anos ou }+ \\
\end{array}$ & \begin{tabular}{|c|} 
Renda Per \\
capita média \\
dos mais \\
pobres
\end{tabular} & $\begin{array}{l}\text { Valor do } \\
\text { Indicador }\end{array}$ & $\begin{array}{c}\text { Evolução de } \\
\text { Empregos } \\
\text { Formais }\end{array}$ & \begin{tabular}{|c|} 
Média de \\
Crescimento \\
do PIB no \\
último \\
triênio \\
\end{tabular} & $\begin{array}{c}\text { PIB per } \\
\text { capita }\end{array}$ & $\begin{array}{l}\text { Valor do } \\
\text { Indicador }\end{array}$ & $\begin{array}{c}\text { Receita de } \\
\text { ICMS per } \\
\text { capita }\end{array}$ & $\begin{array}{c}\text { Receita } \\
\text { de ISS per } \\
\text { capita }\end{array}$ & $\begin{array}{l}\text { Valor do } \\
\text { Indicador }\end{array}$ & & \\
\hline Água Boa & 0,116 & 0,141 & 0,050 & 0,108 & 0,120 & 0,194 & 0,056 & 0,129 & 0,002 & 0,009 & 0,003 & 0,241 & 0,060 \\
\hline Alto Boa Vista & 0,131 & 0,057 & 0,192 & 0,133 & 0,068 & 0,165 & 0,018 & 0,088 & 0,001 & 0,006 & 0,002 & 0,223 & 0,056 \\
\hline Bom Jesus do Araguaia & 0,171 & 0,073 & 0,032 & 0,096 & 0,333 & 0,068 & 0,033 & 0,152 & 0,000 & 0,006 & 0,002 & 0,250 & 0,063 \\
\hline Campinápolis & 0,092 & 0,054 & 0,178 & 0,113 & 0,161 & 0,210 & 0,009 & 0,133 & 0,013 & 0,002 & 0,005 & 0,251 & 0,063 \\
\hline Canabrava do Norte & 0,075 & 0,042 & 0,142 & 0,090 & 0,075 & 0,217 & 0,038 & 0,115 & 0,003 & 0,012 & 0,004 & 0,210 & 0,053 \\
\hline Canarana & 0,134 & 0,180 & 0,116 & 0,150 & 0,098 & 0,144 & 0,054 & 0,103 & 0,001 & 0,010 & 0,003 & 0,257 & 0,064 \\
\hline Cocalinho & 0,092 & 0,069 & 0,059 & 0,077 & 0,073 & 0,209 & 0,049 & 0,116 & 0,006 & 0,007 & 0,004 & 0,197 & 0,049 \\
\hline \begin{tabular}{|l|} 
Confresa \\
\end{tabular} & 0,105 & 0,094 & 0,143 & 0,120 & 0,016 & 0,208 & 0,016 & 0,084 & 0,001 & 0,007 & 0,002 & 0,206 & 0,052 \\
\hline Gaúcha do Norte & 0,123 & 0,159 & 0,300 & 0,204 & 0,125 & 0,112 & 0,039 & 0,096 & 0,001 & 0,005 & 0,002 & 0,302 & 0,075 \\
\hline Luciára & 0,000 & 0,038 & 0,060 & 0,034 & 0,141 & 0,213 & 0,013 & 0,128 & 0,031 & 0,005 & 0,011 & 0,173 & 0,043 \\
\hline Nova Nazaré & 0,116 & 0,000 & 0,113 & 0,080 & 0,127 & 0,040 & 0,110 & 0,097 & 0,000 & 0,001 & 0,000 & 0,178 & 0,044 \\
\hline \begin{tabular}{|l|} 
Nova Xavantina \\
\end{tabular} & 0,109 & 0,048 & 0,031 & 0,066 & 0,067 & 0,126 & 0,104 & 0,104 & 0,002 & 0,015 & 0,005 & 0,175 & 0,044 \\
\hline Novo Santo Antônio & 0,063 & 0,027 & 0,038 & 0,045 & 0,032 & 0,266 & 0,020 & 0,111 & 0,000 & 0,006 & 0,002 & 0,158 & 0,039 \\
\hline \begin{tabular}{|l|} 
Porto Alegre do Norte \\
\end{tabular} & 0,140 & 0,002 & 0,105 & 0,087 & 0,124 & 0,205 & 0,021 & 0,122 & 0,007 & 0,020 & 0,008 & 0,217 & 0,054 \\
\hline Querência & 0,146 & 0,085 & 0,182 & 0,145 & 0,092 & 0,203 & 0,026 & 0,113 & 0,002 & 0,009 & 0,003 & 0,260 & 0,065 \\
\hline Ribeirão Cascalheira & 0,103 & 0,095 & 0,166 & 0,127 & 0,047 & 0,127 & 0,016 & 0,066 & 0,004 & 0,020 & 0,007 & 0,201 & 0,050 \\
\hline Santa Cruz do Xingu & 0,075 & 0,207 & 0,133 & 0,145 & 0,177 & 0,191 & 0,080 & 0,157 & 0,000 & 0,000 & 0,000 & 0,302 & 0,076 \\
\hline Santa Terezinha & 0,104 & 0,207 & 0,135 & 0,156 & 0,115 & 0,156 & 0,052 & 0,113 & 0,007 & 0,010 & 0,005 & 0,274 & 0,069 \\
\hline São Félix do Araguaia & 0,132 & 0,207 & 0,208 & 0,192 & 0,113 & 0,016 & 0,132 & 0,091 & 0,014 & 0,015 & 0,009 & 0,292 & 0,073 \\
\hline \begin{tabular}{|l|} 
São José do Xingu \\
\end{tabular} & 0,090 & 0,037 & 0,041 & 0,058 & 0,085 & 0,110 & 0,249 & 0,155 & 0,000 & 0,001 & 0,000 & 0,214 & 0,054 \\
\hline \begin{tabular}{|l|} 
Serra Nova Dourada \\
\end{tabular} & 0,045 & 0,088 & 0,092 & 0,079 & 0,134 & 0,089 & 0,045 & 0,094 & 0,000 & 0,001 & 0,000 & 0,172 & 0,043 \\
\hline \begin{tabular}{|l|} 
Vila Rica \\
\end{tabular} & 0,085 & 0,110 & 0,023 & 0,076 & 0,043 & 0,260 & 0,052 & 0,124 & 0,001 & 0,017 & 0,005 & 0,206 & 0,051 \\
\hline
\end{tabular}

Quadro 10 Dimensão Econômica do ISMA para o Norte Araguaia.

Fonte: FARIA, et al 2013

\begin{tabular}{llll} 
Revista de Estudos Sociais Ano $2016 \quad$ N.36 V.18 \\
\hline
\end{tabular} 


\subsection{O Norte Araguaia e o ISMA Ambiental}

O bem estar da população perpassa pela garantia da oferta de serviços públicos de qualidade a Dimensão Ambiental do ISMA possui três subdimensões temas que avaliam o saneamento básico, Preservação Ambiental e Gestão Ambiental. No entanto o quadro 11 demonstra um cenário onde a população tem enfrentado dificuldades de acesso e uso adequado dos serviços dessa política pública aqui elencados.

A subdimensão Saneamento Básico conta em sua composição com três indicadores: percentual de domicílios atendidos direta ou indiretamente por coleta de lixo domiciliar, percentual de domicílios com acesso a rede geral de esgoto ou fossa séptica e percentual de domicílios atendidos por rede pública de água. A disponibilização e acesso à água potável e de qualidade pela população da região do Norte Araguaia é um grande problema a ser enfrentado. Os municípios que apresentam melhor desempenho nesta dimensão citam-se: Nova Xavantina 0,242, Água Boa 0,230, Luciára 0,224 e Ribeirão Cascalheira com 0,217 possuindo melhores resultados em domicílios particulares permanentes atendidos pelo serviço. Os municípios com piores nessa subdimensão foram: Novo Santo Antônio 0,085, Canabrava do Norte 0,084 e Bom Jesus do Araguaia com 0,06, porém todos os municípios da região vêm encontrando sérios problemas não somente quanto à coleta dos resíduos sólidos, mas também, com relação à destinação e disposição final no meio ambiente, visto que, a grande maioria dos municípios depositam os resíduos a céu aberto sem tratamento sanitário adequado. 


\begin{tabular}{|c|c|c|c|c|c|c|c|c|c|c|c|c|}
\hline \multicolumn{13}{|c|}{ DIMENSÃO AMBIENTAL } \\
\hline \multirow[b]{2}{*}{ MUNICÍPIO } & \multicolumn{4}{|c|}{ Saneamento Básico } & \multicolumn{3}{|c|}{ Preservação Ambiental } & \multicolumn{3}{|c|}{ Gestão Ambiental } & \multirow[b]{2}{*}{$\begin{array}{c}\text { Valor da } \\
\text { Subdimensão } \\
\text { na } \\
\text { Dimensão }\end{array}$} & \multirow[b]{2}{*}{$\begin{array}{c}\text { Valor da } \\
\text { Dimensão }\end{array}$} \\
\hline & \begin{tabular}{|c}
$\%$ de \\
domićlilios \\
atendidos \\
direta ou \\
indiretamente \\
por coleta de \\
lixo domiciliar.
\end{tabular} & \begin{tabular}{|c|}
$\%$ de \\
domicílio s \\
com acesso a \\
rede geral de \\
esgoto ou \\
fossa séptica \\
\end{tabular} & $\begin{array}{c}\quad \% \text { de } \\
\text { domicílios } \\
\text { atendidos por } \\
\text { rede pública } \\
\text { de água }\end{array}$ & $\begin{array}{c}\text { Valor da } \\
\text { Subdimensão }\end{array}$ & \begin{tabular}{|c|} 
Área \\
desmatada no \\
município em \\
relação à área \\
total \\
desmatada no \\
estado no \\
\end{tabular} & $\begin{array}{c}\text { Expansão do } \\
\text { desmatament } \\
\text { o no último } \\
\text { triênio }\end{array}$ & $\begin{array}{l}\text { Valor do } \\
\text { Indicador }\end{array}$ & \begin{tabular}{|c} 
Efetividade da \\
Estrutura de \\
Gestão \\
Ambiental
\end{tabular} & \begin{tabular}{|c} 
Efetividade do \\
Conselho \\
Municipalde \\
Meio \\
Ambiente
\end{tabular} & $\begin{array}{l}\text { Valor do } \\
\text { Indicador }\end{array}$ & & \\
\hline Água Boa & 0,233 & 0,060 & 0,28 & 0,230 & 0,398 & 0,600 & 0,399 & 0,286 & 0,375 & 0,13 & 0,761 & 0,190 \\
\hline Alto Boa Vista & 0,158 & 0,111 & 0,15 & 0,167 & 0,339 & 0,534 & 0,349 & 0,357 & 0,500 & 0,17 & 0,687 & 0,172 \\
\hline Bom Jesus do Araguaia & 0,147 & 0,008 & 0,00 & 0,062 & 0,257 & 0,548 & 0,322 & 0,357 & 0,500 & 0,17 & 0,556 & 0,139 \\
\hline Campinápolis & 0,105 & 0,053 & 0,16 & 0,128 & 0,400 & 0,600 & 0,400 & 0,286 & 0,500 & 0,16 & 0,685 & 0,171 \\
\hline Canabrava do Norte & 0,140 & 0,003 & 0,07 & 0,084 & 0,314 & 0,565 & 0,352 & 0,429 & 0,500 & 0,19 & 0,621 & 0,155 \\
\hline Canarana & 0,231 & 0,019 & 0,26 & 0,202 & 0,301 & 0,598 & 0,360 & 0,214 & 0,250 & 0,09 & 0,655 & 0,164 \\
\hline Cocalinho & 0,153 & 0,007 & 0,14 & 0,121 & 0,388 & 0,589 & 0,391 & 0,429 & 0,500 & 0,19 & 0,697 & 0,174 \\
\hline Confresa & 0,157 & 0,099 & 0,11 & 0,147 & 0,204 & 0,519 & 0,289 & 0,357 & 0,500 & 0,17 & 0,608 & 0,152 \\
\hline Gaúcha do Norte & 0,113 & 0,046 & 0,19 & 0,141 & 0,215 & 0,552 & 0,307 & 0,357 & 0,500 & 0,17 & 0,619 & 0,155 \\
\hline \begin{tabular}{|l|} 
Luciára \\
\end{tabular} & 0,252 & 0,002 & 0,31 & 0,224 & 0,398 & 0,596 & 0,398 & 0,143 & 0,000 & 0,03 & 0,650 & 0,163 \\
\hline Nova Nazaré & 0,091 & 0,036 & 0,18 & 0,121 & 0,389 & 0,598 & 0,395 & 0,286 & 0,500 & 0,16 & 0,673 & 0,168 \\
\hline Nova Xavantina & 0,218 & 0,103 & 0,28 & 0,242 & 0,358 & 0,582 & 0,376 & 0,143 & 0,125 & 0,05 & 0,671 & 0,168 \\
\hline Novo Santo Antônio & 0,146 & 0,052 & 0,02 & 0,085 & 0,390 & 0,571 & 0,384 & 0,286 & 0,000 & 0,06 & 0,527 & 0,132 \\
\hline \begin{tabular}{|l} 
Porto Alegre do Norte \\
\end{tabular} & 0,182 & 0,020 & 0,19 & 0,156 & 0,354 & 0,585 & 0,376 & 0,357 & 0,375 & 0,15 & 0,678 & 0,170 \\
\hline Querência & 0,176 & 0,025 & 0,20 & 0,161 & 0,133 & 0,483 & 0,246 & 0,286 & 0,500 & 0,16 & 0,565 & 0,141 \\
\hline Ribeirão Cascalheira & 0,176 & 0,157 & 0,21 & 0,217 & 0,314 & 0,568 & 0,353 & 0,286 & 0,375 & 0,13 & 0,702 & 0,176 \\
\hline Santa Cruz do Xingu & 0,147 & 0,132 & 0,23 & 0,204 & 0,329 & 0,569 & 0,359 & 0,357 & 0,250 & 0,12 & 0,684 & 0,171 \\
\hline Santa Terezinha & 0,090 & 0,195 & 0,16 & 0,177 & 0,265 & 0,551 & 0,327 & 0,286 & 0,500 & 0,16 & 0,661 & 0,165 \\
\hline São Félix do Araguaia & 0,101 & 0,075 & 0,20 & 0,152 & 0,167 & 0,507 & 0,270 & 0,143 & 0,125 & 0,05 & 0,475 & 0,110 \\
\hline \begin{tabular}{|l|} 
São José do Xingu \\
\end{tabular} & 0,181 & 0,017 & 0,26 & 0,183 & 0,173 & 0,552 & 0,290 & 0,357 & 0,500 & 0,17 & 0,645 & 0,161 \\
\hline Serra Nova Dourada & 0,111 & 0,036 & 0,19 & 0,136 & 0,384 & 0,528 & 0,365 & 0,214 & 0,250 & 0,09 & 0,594 & 0,148 \\
\hline Vila Rica & 0,184 & 0,168 & 0,05 & 0,160 & 0,157 & 0,546 & 0,281 & 0,286 & 0,250 & 0,11 & 0,548 & 0,137 \\
\hline
\end{tabular}

Quadro 11 Dimensão Ambiental do ISMA para o Norte Araguaia.

Fonte: FARIA, et al 2013a

\begin{tabular}{llll} 
Revista de Estudos Sociais Ano $2016 \quad$ N.36 V.18 \\
\hline
\end{tabular} 
Avaliar a situação a degradação ambiental no município e a capacidade de sustentabilidade ecológica é função da subdimensão Preservação Ambiental do ISMA, que integra duas variáveis: Área desmatada no município em relação à área total desmatada no estado no mesmo período e Expansão do desmatamento no último triênio. Os melhores resultados para esta dimensão foram obtidos pelos municípios de: Campinápolis 0,400, Água Boa 0,399, Luciára 0,398 e Nova Nazaré com 0,395, já para Vila Rica 0,281, São Félix do Araguaia 0,270 e Querência 0,246 restaram as últimas posições nesse quesito na região.

As variáveis que compõem a subdimensão Gestão Ambiental são binárias, sua formação se dá através da resposta sim igual a 1 ou não igual a 0 . Para questões que avaliam a efetividade dos conselhos, onde as duas variáveis possuem sete questionamentos com peso de cinquenta por cento, os municípios com maior números de respostas positivas foram: Canabrava do Norte, Cocalinho, Alto Boa Vista e Bom Jesus do Araguaia.

Esses dados demonstram a fragilidade do sistema de saneamento, requerendo, neste caso em específico, ações objetivando a ampliação dos equipamentos públicos de saneamento ambiental, ou seja, tratamento e abastecimento de água potável, coleta, destinação e disposição final dos resíduos sólidos urbanos e do esgotamento sanitário bem como o devido manejo das águas pluviais. Quanto à eficácia da preservação e gestão ambiental, é preciso que os gestores municipais, assim com a sociedade envolvida no funcionamento dos conselhos municipais de meio ambiente, tenham melhor desempenho, participando, fiscalizando e coordenando as ações destes, uma variável que não é levada em conta dentro do ISMA é a destinação da coleta de lixo, uma situação que é vivida por toda a Amazônia Legal é a de que a grande maioria dos municípios ainda faz uso de lixão, agregar esta variável a dimensão daria maior visibilidade a esta dificuldade favorecendo num segundo momento políticas de saneamento básico.

\subsection{O Norte Araguaia e o ISMA Sociocultural}

Equidade no acesso aos serviços oferecidos a população, melhoria na qualidade de vida, composta por seis indicadores organizados em quatro subdimensões, a Dimensão Sociocultural do ISMA carrega consigo variáveis que buscam mensurar a satisfação das necessidades humanas, melhoria da qualidade de vida, saúde, educação e adequação das moradias. 
As subdimensões Longevidade e Mortalidade infantil integram dois indicadores: esperança de vida ao nascer e mortalidade infantil. Estes índices revelam se há uma relação positiva com o desenvolvimento local, pois é influenciado pelas condições sociais, ambientais e econômicas, os municípios que apresentaram um bom resultado foram: São Félix do Araguaia, Gaúcha do Norte, Querência, Ribeirão Cascalheira.

Escolaridade e Qualidade do Ensino são duas subdimensões do ISMA Sociocultural, elas são termômetros da educação, sua função é medir o grau de alfabetização da população adulta, a evasão escolar e o aproveitamento do ensino, evidenciando o nível de acesso da população a educação, desde infantil a adultos, condição fundamental para que a população tenha melhores condições de serem inseridas no mercado de trabalho e de equidade social. Os municípios que tiveram melhores índices foram: Água Boa, Querência, Vila Rica e Santa Cruz do Xingu, já para os municípios de Gaúcha do Norte, Nova Nazaré e Campinápolis há um longo caminho a percorrer pois estes tiveram um resultado muito baixo no indicador que mede a quantidade de pessoas de 15 anos ou mais que não sabem ler e escrever, investimentos em programas de EJA (educação de jovens e adultos) já resultariam em uma melhora para este índice.

Dentro do desenvolvimento sustentável, moradia adequada é também fator determinante para a melhoria da qualidade de vida. No ISMA são utilizados quatro indicadores binários que mensuram a evolução desta dimensão, respostas positivas ou negativas para estas questões, Existência de Plano Municipal de Habitação; Existência de Conselho Municipal de Habitação; Existência de Fundo Municipal de Habitação e Existência de Cadastro ou Levantamento de famílias interessadas em programas de Habitação. Os municípios de Água Boa, Gaúcha do Norte, Nova Xavantina e Querência ficam com a melhor colocação, respondendo positivamente aos quatro indicadores, Bom Jesus do Araguaia, Canabrava do Norte, Novo Santo Antônio, Santa Cruz do Xingu e São José do Xingu com uma resposta positiva e Santa Terezinha sem resposta positiva para os questionamentos destas. 


\begin{tabular}{|c|c|c|c|c|c|c|c|c|c|c|c|c|c|c|c|c|c|c|}
\hline \multicolumn{19}{|c|}{ DIMENSÃO SOCIOCULTURAL } \\
\hline \multirow[b]{2}{*}{ MUNICÍPIO } & \multicolumn{2}{|c|}{ Longevidade } & \multicolumn{2}{|c|}{ Mortalidade Infantil } & \multicolumn{2}{|c|}{ Escolaridade } & \multicolumn{4}{|c|}{ Qualidade do Ensino } & \multicolumn{5}{|c|}{ Estrutura de Gestão para políticas habitacionais } & \multicolumn{2}{|c|}{ Infraestrutura cultural } & \multirow[b]{2}{*}{\begin{tabular}{|c} 
Valor da \\
Dimensão
\end{tabular}} \\
\hline & $\begin{array}{c}\text { Índice de } \\
\text { Esper.de vida } \\
\text { ao nascer }\end{array}$ & $\begin{array}{l}\text { Valor } \\
\text { Indicador }\end{array}$ & $\begin{array}{c}\text { Mortali- dade } \\
\text { Infantil }\end{array}$ & $\begin{array}{c}\text { Valor } \\
\text { Indicador }\end{array}$ & $\begin{array}{c}\text { Pessoas de } \\
15 \text { anos ou } \\
\text { mais que não } \\
\text { sabem lere } \\
\text { escrever }\end{array}$ & $\begin{array}{l}\text { Valor do } \\
\text { Indicador }\end{array}$ & \begin{tabular}{|c|} 
Índice de \\
Apro- \\
veitamento \\
do Ens ino \\
Bás ico - IDEB \\
\end{tabular} & \begin{tabular}{|c}
$\%$ de \\
abandono \\
escolarde $6^{2}$ \\
a 9 9 série
\end{tabular} & \begin{tabular}{|c|}
$\%$ de \\
abandono \\
escolar no \\
ensino médio
\end{tabular} & $\begin{array}{l}\text { Valor do } \\
\text { Indicador }\end{array}$ & $\begin{array}{c}\text { Exisistencia de } \\
\text { Plano } \\
\text { Municipalde } \\
\text { Habitação }\end{array}$ & $\begin{array}{c}\text { Existência de } \\
\text { Conselho } \\
\text { Municipalde } \\
\text { Habitação }\end{array}$ & $\begin{array}{c}\text { Exisiência de } \\
\text { Fundo } \\
\text { Municipal de } \\
\text { Habitação }\end{array}$ & \begin{tabular}{|c|} 
Exist de Cad \\
ou Lev. de \\
famílias \\
interessadas \\
em prog de \\
Habitação \\
\end{tabular} & $\begin{array}{l}\text { Valor do } \\
\text { Indicador }\end{array}$ & $\begin{array}{c}\text { Exis tência de } \\
\text { Equip. } \\
\text { Sociocultu- } \\
\text { rais }\end{array}$ & $\begin{array}{l}\text { Valor do } \\
\text { Indicador }\end{array}$ & \\
\hline Água Boa & 0,710 & 0,355 & 0,742 & 0,371 & 0,800 & 0,400 & 0,197 & 0,299 & 0,350 & 0,423 & 0,250 & 0,250 & 0,250 & 0,250 & 1,000 & 0,333 & 0,333 & 0,183 \\
\hline Alto Boa Vista & 0,446 & 0,223 & 0,485 & 0,242 & 0,628 & 0,314 & 0,145 & 0,249 & 0,308 & 0,351 & 0,250 & 0,000 & 0,000 & 0,250 & 0,500 & 0,333 & 0,333 & 0,126 \\
\hline Bom Jesus do Araguaia & 0,240 & 0,120 & 0,268 & 0,134 & 0,673 & 0,337 & 0,093 & 0,342 & 0,350 & 0,393 & 0,250 & 0,000 & 0,000 & 0,000 & 0,250 & 0,333 & 0,333 & 0,103 \\
\hline Campinápolis & 0,441 & 0,220 & 0,474 & 0,237 & 0,033 & 0,016 & 0,124 & 0,167 & 0,147 & 0,219 & 0,000 & 0,250 & 0,000 & 0,250 & 0,500 & 0,333 & 0,333 & 0,094 \\
\hline Canabrava do Norte & 0,587 & 0,294 & 0,629 & 0,314 & 0,636 & 0,318 & 0,083 & 0,206 & 0,234 & 0,261 & 0,250 & 0,000 & 0,000 & 0,000 & 0,250 & 0,333 & 0,333 & 0,118 \\
\hline Canarana & 0,675 & 0,337 & 0,701 & 0,351 & 0,683 & 0,342 & 0,238 & 0,229 & 0,208 & 0,338 & 0,000 & 0,250 & 0,250 & 0,250 & 0,750 & 0,667 & 0,667 & 0,173 \\
\hline Cocalinho & 0,481 & 0,240 & 0,515 & 0,258 & 0,427 & 0,213 & 0,114 & 0,307 & 0,324 & 0,373 & 0,250 & 0,000 & 0,000 & 0,250 & 0,500 & 0,333 & 0,333 & 0,123 \\
\hline Confresa & 0,537 & 0,268 & 0,577 & 0,289 & 0,627 & 0,314 & 0,134 & 0,187 & 0,243 & 0,282 & 0,250 & 0,000 & 0,000 & 0,250 & 0,500 & 0,333 & 0,333 & 0,128 \\
\hline Gaúcha do Norte & 0,899 & 0,449 & 0,907 & 0,454 & 0,089 & 0,044 & 0,176 & 0,253 & 0,235 & 0,332 & 0,250 & 0,250 & 0,250 & 0,250 & 1,000 & 0,333 & 0,333 & 0,163 \\
\hline Luciára & 0,287 & 0,143 & 0,320 & 0,160 & 0,539 & 0,270 & 0,062 & 0,066 & 0,335 & 0,232 & 0,250 & 0,250 & 0,000 & 0,250 & 0,750 & 0,333 & 0,333 & 0,114 \\
\hline \begin{tabular}{|l|} 
Nova Nazaré \\
\end{tabular} & 0,341 & 0,170 & 0,371 & 0,186 & 0,088 & 0,044 & 0,083 & 0,276 & 0,350 & 0,354 & 0,000 & 0,250 & 0,250 & 0,250 & 0,750 & 0,333 & 0,333 & 0,111 \\
\hline Nova Xavantina & 0,411 & 0,205 & 0,454 & 0,227 & 0,662 & 0,331 & 0,176 & 0,292 & 0,325 & 0,396 & 0,250 & 0,250 & 0,250 & 0,250 & 1,000 & 0,333 & 0,333 & 0,154 \\
\hline Novo Santo Antônio & 0,715 & 0,358 & 0,742 & 0,371 & 0,581 & 0,291 & 0,000 & 0,249 & 0,350 & 0,299 & 0,250 & 0,000 & 0,000 & 0,000 & 0,250 & 0,333 & 0,333 & 0,128 \\
\hline Porto Alegre do Norte & 0,437 & 0,219 & 0,474 & 0,237 & 0,671 & 0,335 & 0,134 & 0,288 & 0,282 & 0,352 & 0,250 & 0,000 & 0,000 & 0,250 & 0,500 & 0,333 & 0,333 & 0,127 \\
\hline Querência & 0,794 & 0,397 & 0,814 & 0,407 & 0,778 & 0,389 & 0,238 & 0,323 & 0,179 & 0,370 & 0,250 & 0,250 & 0,250 & 0,250 & 1,000 & 0,333 & 0,333 & 0,184 \\
\hline Ribeirão Cascalheira & 0,736 & 0,368 & 0,763 & 0,381 & 0,614 & 0,307 & 0,134 & 0,237 & 0,210 & 0,291 & 0,250 & 0,250 & 0,000 & 0,250 & 0,750 & 0,333 & 0,333 & 0,155 \\
\hline Santa Cruz do Xingu & 0,708 & 0,354 & 0,742 & 0,371 & 0,744 & 0,372 & 0,021 & 0,350 & 0,350 & 0,360 & 0,250 & 0,000 & 0,000 & 0,000 & 0,250 & 0,333 & 0,333 & 0,138 \\
\hline Santa Terezinha & 0,706 & 0,353 & 0,761 & 0,381 & 0,458 & 0,229 & 0,072 & 0,101 & 0,308 & 0,241 & 0,000 & 0,000 & 0,000 & 0,000 & 0,000 & 0,333 & 0,333 & 0,107 \\
\hline São Félix do Araguaia & 0,911 & 0,455 & 0,918 & 0,459 & 0,584 & 0,292 & 0,103 & 0,198 & 0,254 & 0,278 & 0,000 & 0,250 & 0,250 & 0,250 & 0,750 & 0,667 & 0,667 & 0,182 \\
\hline São José do Xingu & 0,577 & 0,288 & 0,619 & 0,309 & 0,603 & 0,301 & 0,083 & 0,191 & 0,151 & 0,212 & 0,250 & 0,000 & 0,000 & 0,000 & 0,250 & 0,333 & 0,333 & 0,112 \\
\hline Serra Nova Dourada & 0,607 & 0,303 & 0,639 & 0,320 & 0,594 & 0,297 & 0,031 & 0,229 & 0,145 & 0,203 & 0,250 & 0,000 & 0,000 & 0,250 & 0,500 & 0,333 & 0,333 & 0,126 \\
\hline Vila Rica & 0,715 & 0,358 & 0,742 & 0,371 & 0,736 & 0,368 & 0,166 & 0,303 & 0,295 & 0,382 & 0,250 & 0,250 & 0,000 & 0,250 & 0,750 & 0,333 & 0,333 & 0,165 \\
\hline
\end{tabular}

\section{Quadro 12 Dimensão Sociocultural do ISMA para o Norte Araguaia.}

Fonte: FARIA, et al 2013a 


\section{ANÁLISES: O ISMA FINAL DO NORTE ARAGUAIA}

Resultado das somas das dimensões Político-Institucional, Econômica, Ambiental E Sociocultural ajustadas ao seu peso temos o Índice de Sustentabilidade da Amazônia, porém no quadro 13 os valores das dimensões encontram-se sem ajuste de peso e coloridas conforme a classificação do ISMA, afim de facilitar a compreensão desses dados, com as cores vermelho para muito baixo, laranja para baixo, amarelo para médio e verde para alto índice de sustentabilidade, apenas para uma melhor compreensão da performance dos resultados.

\begin{tabular}{|c|c|c|c|c|c|}
\hline & $\begin{array}{c}\text { Político- } \\
\text { Institucional }\end{array}$ & Econômica & Ambiental & Sociocultural & ISMA \\
\hline Mato Grosso & 0,192 & 0,244 & 0,668 & 0,600 & 0,427 \\
\hline Água Boa & 0,2404 & 0,2406 & 0,7614 & 0,7314 & 0,4934 \\
\hline Alto Boa Vista & 0,1330 & 0,2230 & 0,6874 & 0,5057 & 0,3873 \\
\hline Bom Jesus do Araguaia & 0,1510 & 0,2504 & 0,5557 & 0,4116 & 0,3422 \\
\hline Campinápolis & 0,2000 & 0,2520 & 0,6840 & 0,3760 & 0,3780 \\
\hline Canabrava do Norte & 0,1167 & 0,2102 & 0,6214 & 0,4730 & 0,3553 \\
\hline Canarana & 0,3221 & 0,2571 & 0,6547 & 0,6936 & 0,4819 \\
\hline Cocalinho & 0,1269 & 0,1971 & 0,6972 & 0,4919 & 0,3783 \\
\hline Confresa & 0,1724 & 0,2064 & 0,6075 & 0,5125 & 0,3747 \\
\hline Gaúcha do Norte & 0,1702 & 0,3020 & 0,6193 & 0,6504 & 0,4355 \\
\hline Luciara & 0,1808 & 0,1735 & 0,6504 & 0,4580 & 0,3657 \\
\hline Nova Nazaré & 0,2591 & 0,1776 & 0,6729 & 0,4431 & 0,3882 \\
\hline Nova Xavantina & 0,3232 & 0,1749 & 0,6714 & 0,6146 & 0,4460 \\
\hline Novo Santo Antonio & 0,1470 & 0,1578 & 0,5266 & 0,5123 & 0,3359 \\
\hline Porto Alegre do Norte & 0,1574 & 0,2169 & 0,6782 & 0,5095 & 0,3905 \\
\hline Querência & 0,2211 & 0,2604 & 0,5646 & 0,7356 & 0,4454 \\
\hline Ribeirão Cascalheira & 0,2173 & 0,2009 & 0,7022 & 0,6209 & 0,4353 \\
\hline Santa Cruz do Xingu & 0,0653 & 0,3023 & 0,6843 & 0,5540 & 0,4015 \\
\hline Santa Terezinha & 0,1121 & 0,2740 & 0,6607 & 0,2076 & 0,3136 \\
\hline São Félix do Araguaia & 0,2067 & 0,2918 & 0,4749 & 0,7285 & 0,4255 \\
\hline São José do Xingu & 0,1290 & 0,2142 & 0,6449 & 0,4500 & 0,3595 \\
\hline Serra Nova Dourada & 0,0947 & 0,1725 & 0,5938 & 0,5035 & 0,3411 \\
\hline
\end{tabular}




\begin{tabular}{|r|c|c|c|c|c|}
\hline Vila Rica & 0,2474 & 0,2060 & 0,5482 & 0,6603 & 0,4155 \\
\hline
\end{tabular}

Quadro 13 ISMA de Mato Grosso e Municípios do Norte Araguaia.

Fonte: FARIA, et al 2013a

A classificação dos índices em níveis de sustentabilidade foi representada por cores permitindo uma melhor compreensão dos resultados e dos níveis de sustentabilidade dos municípios e do Estado como um todo. A aplicação revelou que os municípios de Agua Boa e Canarana apresentam uma situação melhor que os demais municípios, ainda mais levando se em conta o índice obtido por Santa Terezinha que obteve no geral um índice muito baixo conforme os parâmetros estabelecidos na metodologia do ISMA.

É extremamente necessário ressaltar que com exceção da dimensão ambiental todas as outras dimensões do ISMA para região Norte Araguaia assim como para o Estado de Mato Grosso, apresentaram resultados insatisfatórios o que evidencia que é preciso questionar a eficiência das políticas públicas implementadas, assim como integrar a sociedade como um todo nas tomadas de decisões, para que num curto prazo de tempo possa se vislumbrar uma melhoria nestes resultado.

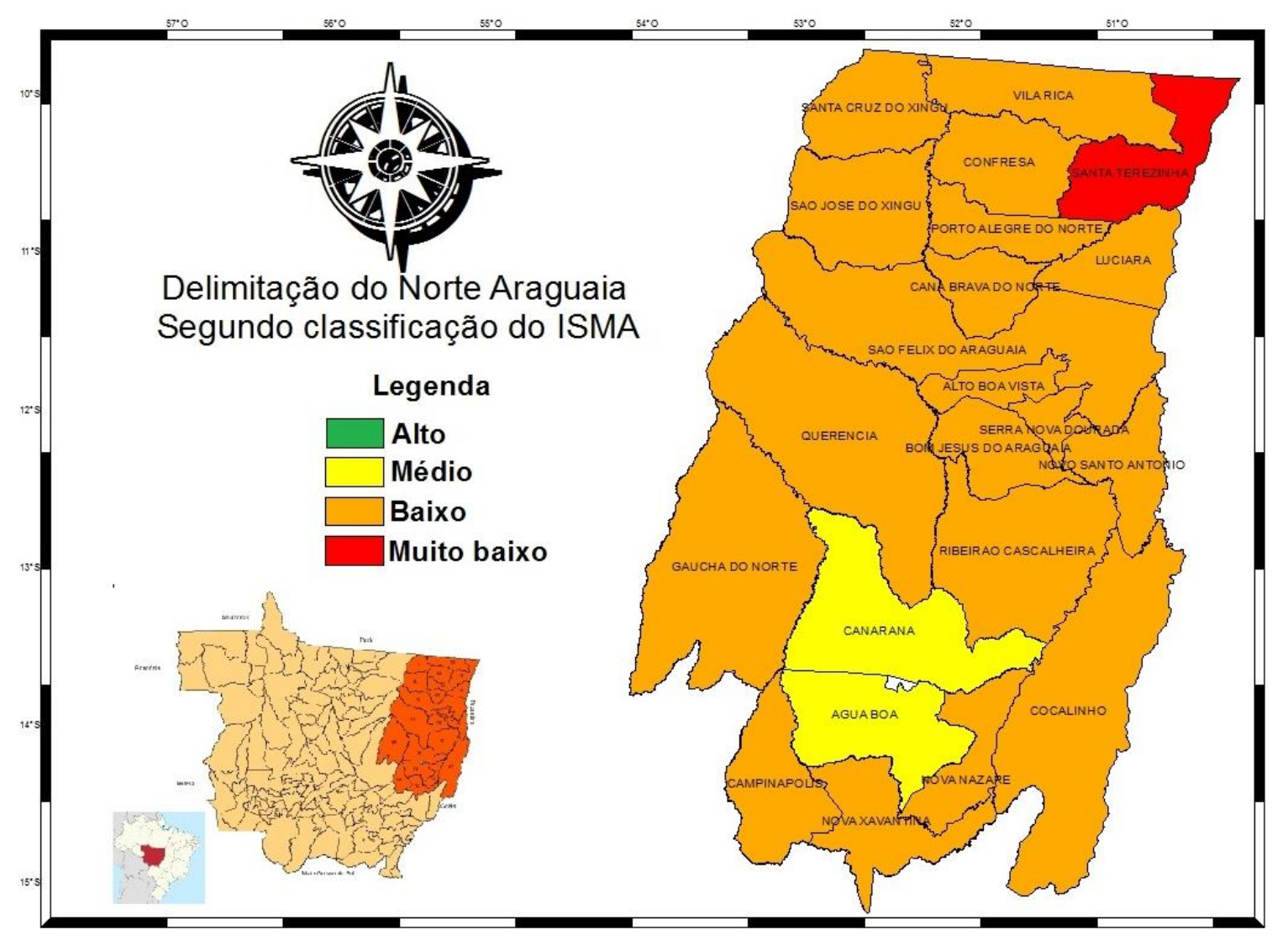

Figura 3 Mapa no Norte Araguaia segundo a classificação do ISMA 
Fonte: IMEA, FARIA, et al 2013a, elaborado pelo autor.

A figura 3 apresenta os munícipios da Região Norte Araguaia coloridos segundo a classificação do ISMA, onde Canarana e Água Boa apresentam um índice médio de desenvolvimento sustentável, Santa Terezinha muito baixo e os outros 19 munícipios com um baixo resultado de sustentabilidade.

\subsection{IDH Médio X ISMA Baixo}

Considerando as críticas que são feitas ao IDH é preciso enfatizar que este possui um número reduzido de dimensões e indicadores que o compõe, outra crítica ao índice está no fato dele não incorporar a questão ambiental em sua metodologia, tornando-se insuficiente como medida de desenvolvimento sustentável. As poucas variáveis do IDH refletem a condição média de uma dada população, ainda mais quando houver neste grupo grandes disparidades sociais, escondendo outras variações existentes fazendo com que o indicador seja extremamente otimista. "A média dos três indicadores pode, eventualmente, ocultar importantes tendências dentro do desenvolvimento da população." (RIBEIRO, 2002, p.10).

\begin{tabular}{|c|c|c|c|c|c|c|c|c|c|}
\hline \multirow[b]{2}{*}{ UF / Município } & \multicolumn{4}{|c|}{ IDH } & \multicolumn{5}{|c|}{ ISMA } \\
\hline & Educação & Longevidade & Renda & IDHM & $\begin{array}{l}\text { Político- } \\
\text { Institucional }\end{array}$ & Econômica & Ambiental & $\begin{array}{l}\text { Socio- } \\
\text { cultural }\end{array}$ & ISMA \\
\hline Mato Grosso & 0,635 & 0,821 & 0,732 & 0,725 & 0,192 & 0,244 & 0,668 & 0,600 & 0,427 \\
\hline Água Boa & 0,646 & 0,829 & 0,723 & 0,729 & 0,240 & 0,241 & 0,761 & 0,731 & 0,493 \\
\hline Alto Boa Vista & 0,561 & 0,803 & 0,613 & 0,651 & 0,133 & 0,223 & 0,687 & 0,506 & 0,387 \\
\hline Bom Jesus do Araguaia & 0,555 & 0,784 & 0,665 & 0,661 & 0,151 & 0,250 & 0,556 & 0,412 & 0,342 \\
\hline Campinápolis & 0,324 & 0,803 & 0,597 & 0,538 & 0,200 & 0,252 & 0,684 & 0,376 & 0,378 \\
\hline Canabrava do Norte & 0,589 & 0,817 & 0,616 & 0,667 & 0,117 & 0,210 & 0,621 & 0,473 & 0,355 \\
\hline Canarana & 0,549 & 0,825 & 0,735 & 0,693 & 0,322 & 0,257 & 0,655 & 0,694 & 0,482 \\
\hline Cocalinho & 0,528 & 0,807 & 0,674 & 0,660 & 0,127 & 0,197 & 0,697 & 0,492 & 0,378 \\
\hline Confresa & 0,556 & 0,812 & 0,660 & 0,668 & 0,172 & 0,206 & 0,608 & 0,513 & 0,375 \\
\hline Gaúcha do Norte & 0,418 & 0,847 & 0,658 & 0,615 & 0,170 & 0,302 & 0,619 & 0,650 & 0,436 \\
\hline Luciara & 0,634 & 0,788 & 0,617 & 0,676 & 0,181 & 0,174 & 0,650 & 0,458 & 0,366 \\
\hline Nova Nazaré & 0,427 & 0,793 & 0,621 & 0,595 & 0,259 & 0,178 & 0,673 & 0,443 & 0,388 \\
\hline Nova Xavantina & 0,613 & 0,800 & 0,713 & 0,704 & 0,323 & 0,175 & 0,671 & 0,615 & 0,446 \\
\hline Novo Santo Antonio & 0,526 & 0,829 & 0,640 & 0,653 & 0,147 & 0,158 & 0,527 & 0,512 & 0,336 \\
\hline Porto Alegre do Norte & 0,587 & 0,803 & 0,647 & 0,673 & 0,157 & 0,217 & 0,678 & 0,510 & 0,391 \\
\hline Querência & 0,565 & 0,837 & 0,701 & 0,692 & 0,221 & 0,260 & 0,565 & 0,736 & 0,445 \\
\hline Ribeirão Cascalheira & 0,542 & 0,831 & 0,668 & 0,670 & 0,217 & 0,201 & 0,702 & 0,621 & 0,435 \\
\hline Santa Cruz do Xingu & 0,550 & 0,828 & 0,704 & 0,684 & 0,065 & 0,302 & 0,684 & 0,554 & 0,402 \\
\hline Santa Terezinha & 0,498 & 0,761 & 0,596 & 0,609 & 0,112 & 0,274 & 0,661 & 0,208 & 0,314 \\
\hline São Félix do Araguaia & 0,538 & 0,848 & 0,652 & 0,668 & 0,207 & 0,292 & 0,475 & 0,729 & 0,426 \\
\hline São José do Xingu & 0,487 & 0,828 & 0,703 & 0,657 & 0,129 & 0,214 & 0,645 & 0,450 & 0,360 \\
\hline Serra Nova Dourada & 0,560 & 0,819 & 0,638 & 0,664 & 0,095 & 0,173 & 0,594 & 0,504 & 0,341 \\
\hline Vila Rica & 0,553 & 0,829 & 0,709 & 0,688 & 0,247 & 0,206 & 0,548 & 0,660 & 0,416 \\
\hline
\end{tabular}

Quadro 14 IDH e ISMA 
Fonte: FARIA et al, PNUD.

As variáveis que compõe os indicadores Educação e Longevidade do IDH, fazem parte da dimensão sociocultural no ISMA que associadas as variáveis que levam em consideração as questões de habitação e cultura, melhor avaliam o desempenho do desenvolvimento humano e são aspectos essenciais do desenvolvimento sustentável, essa dimensão apresentou dados resultados bastante variados, o município de Santa Terezinha obteve um desempenho sociocultural muito baixo no ISMA e em Educação no IDH. Água Boa, Nova Xavantina conseguiram resultados que os classificam com alto desenvolvimento no ISMA e baixo no IDH.

Na observação do quadro 14 a dimensão renda do IDH os municípios do Norte Araguaia apresentaram um desempenho de médio para alto em sua maioria, porém na dimensão econômica do ISMA, onde são colocadas em provas o PPP mais outras variáveis que mensuram a eficiência dos processos produtivos, os resultados alcançados pelos municípios foram muito baixos.

A dimensão ambiental do ISMA foi a que apresentou os melhores resultados, contudo há que se levar em consideração que tal resultado pode não representar a realidade da região, que mesmo contando com bons resultados em coleta de lixo, abastecimento de água potável, baixo desmatamento no último triênio, herdou dos programas de integração e dos projetos de colonização extensas áreas desmatadas e sem contar que todos os municípios da região depositam seu lixo doméstico a céu aberto.

Similar a dimensão ambiental do ISMA, a dimensão político-institucional também obteve resultados muito baixos, sinalizando que muito há que ser feito nessa área. Envolver os Conselhos Paritários nas tomadas de decisões, incentivar a qualificação dos servidores públicos, melhorar a saúde financeira dos municípios incentivando a industrialização afim de melhor a arrecadação de tributos, oferta de empregos.

\section{Conclusões}

Umas das características do desenvolvimento é a de que este processo é um conceito aberto a novas interpretações, fazendo se uma breve análise histórica de sua conceituação, a compreensão do termo, foi ao longo do tempo se adaptando, partindo apenas da preocupação com o crescimento econômico para a realidade das últimas décadas onde se observa uma preocupação com a preservação do meio ambiente, chegando ao que hoje é chamado de 
desenvolvimento sustentável, porém tão complexo quanto conceituação é a forma de mensurá-lo.

Sem essa preocupação com a degradação ambiental, intensificou-se no Brasil durante os Governos Militares a necessidade de integrar as Regiões Centro Oeste e Norte a economia nacional, expandindo a fronteira a agrícola do pais. Essa ocupação baseava-se num modelo exógeno de desenvolvimento, com a implantação de programas de incentivos fiscais, projetos de implantação de infraestrutura e liberação de recursos para aqueles que se dispusessem a expandir seus negócios Amazônia adentro, esse movimento de expansão teve origem no Leste de Mato Grosso.

Essa forma de desenvolvimento exógena com facilitação de créditos apenas favoreceu a formação de latifúndios que desenvolveram na região uma produção de pecuária intensiva ou agricultura de soja, gerando concentração de renda, especulação imobiliária, forte degradação ao meio ambiente, que pouco agregou no desenvolvimento da região. Ao final dos anos 80 , abalados por um crise nacional, sem uma infraestrutura desenvolvida, a finalização de projetos que favoreciam a colonização, encerramento das atividades da SUDAM e sem um aporte do governo do Estado, cresce na região Norte Araguaia, um sentimento de abandono, foi tão forte que gerou uma necessidade de independência institucional com a Federação para a criação de um novo Estado, por diversas vezes líderes políticos da região fizeram com que tramitassem no Congresso Federal e Senado Projetos de Lei que viabilizassem a criação do Estado do Araguaia.

O desenvolvimento sustentável representa a relação existente entre o desenvolvimento econômico e a sustentabilidade. Porém o desafio a este modelo está na dificuldade de sua mensuração, a utilização de indicadores de sustentabilidade objeto deste trabalho é avaliar os prejuízos causados pela maneira como a região Norte Araguaia foi ocupada, haja visto que a herança deixada pelos planos de integração e projetos de colonização foi de grandes áreas devastadas na região, onde o crescimento econômico não se reverteu em desenvolvimento, afim de atender as necessidades da população, para isto foram utilizados dois indicadores como ferramenta de avaliação do desenvolvimento na região, o IDH e o ISMA.

A verificação do IDH revelou uma de suas principais peculiaridades, o Indicador embora muito utilizado não pode servir de balizamento para os municípios por não revelar o verdadeiro grau de desenvolvimento dos mesmos. A dimensão longevidade apresentou resultados muito alto para os municípios da região mascarando os resultados muito baixos em educação de alguns destes. Estes dados por sua vez, conferiram aos municípios uma 
classificação média de desenvolvimento, ficando evidente a dicotomia entre os indicadores, além do IDH não conferir em sua análise, variáveis que mensuram o desenvolvimento ecológico, cultural e espacial da região.

Já a utilização da ferramenta ISMA possibilitou uma visualização do nível de sustentabilidade no Norte Araguaia, a transformação dos indicadores em índices ainda contribuiu para a visualização da realidade local, uma vez que em comparação ao outro indicador analisado, foi possível com a aplicação do indicador rebaixar a condição de desenvolvimento medida pelo IDH.

\section{Referências}

ABREU, S. Planejamento governamental: A Sudeco no espaço Mato-grossense: contexto, propósitos e contradições. Tese em Geografia - Faculdade de Filosofia, Letras e Ciências Humanas da USP, São Paulo, 2001.

AMARAL FILHO, J. do. A endogeneização no desenvolvimento econômico regional e local. In Planejamento e Políticas Públicas (PPP), Jun., 2001.

ALVES Jr. G. T.. O Planejamento governamental e seus reflexos na estrutura fundiária de Mato Grosso. Caminhos de Geografia - Revista On Line. 4(9), p. 17-30, jun/2003 Instituto de Geografia UFU. Disponível em: www.ig.ufu.br/caminhos de geografia.html. BARROZO, J. C.. Exploração e escravidão nas agropecuárias da Amazônia matogrossense. 1992. Dissertação (Mestrado) Universidade Estadual de Campinas, Campinas, 1992.

BARQUERO, A. V. (2001). Desenvolvimento Endógeno em Tempos de Globalização. Trad. Ricardo Brinco. Porto Alegre: Fundação de Economia e Estatística.

BELLEN, Hans Michael Van. Indicadores de Sustentabilidade: Uma Análise Comparativa. Rio de Janeiro. FGV, 2005.

BRASIL, PROJETO DE DECRETO LEGISLATIVO N 850, DE 2001 (Apensos: PDC's n's 49, de 2003; e 495, de 2003) Convoca plebiscito sobre a criação do Estado do Araguaia. SENADO FEDERAL

BRITO, P. Economia brasileira: Planos Econômicos e Políticas Econômicas Básicas. $2^{\mathrm{a}}$ ed. São Paulo-SP: Atlas, 2004.

CAMARGO, A. L. de B. Desenvolvimento sustentável: dimensões e desafios. $2^{\mathrm{a}}$ ed. Campinas-SP: Papirus, 2005.

ENGEL, G.I. Pesquisa-ação. Educar, Curitiba, n.16, 2000.

FARIA, A.M.M. Cálculo do ISMA (Índice de Sustentabilidade dos Municípios da Amazônia) de Mato Grosso. Relatório parcial do projeto "Incubadora de Políticas 
Públicas da Amazônia”. Confeccionado em MS Excel® ${ }^{\circledR}$ Cuiabá: UFMT, 29 de junho, 2013a. Disponível em: http://www.amazonia.ufpa.br/ippa/menu/144.

FARIA, A.M.M. Desempenho Institucional, Crescimento Econômico e Desigualdades Regionais na Amazônia: os municípios mais vulneráveis de Mato Grosso. Quarto relatório da dimensão socioeconômica de Mato Grosso do projeto "Incubadora de Políticas Públicas da Amazônia". Cuiabá: UFMT, 25 de agosto, 2013. En linea http://www.eumed.net/rev/delos/22/alta-floresta.html visita em 18/04/2016

FARIA, A.M.M. Perspectivas para o Desenvolvimento de Mato Grosso. In: BNDES. (Org.). Um olhar territorial para o desenvolvimento: Região Centro-Oeste. 1ed. Rio de Janeiro: BNDES, 2014, v.1, p.472-501.

FARIA, A.M.M.; RIBEIRO, A.R.; IRIGARAY, C.T.J.H.; SILVA, C.J.; SOARES, C.R.A. Sustentabilidade dos municípios e vulnerabilidade regional no estado de Mato Grosso: Amazônia mato-grossense e a região de Alta Floresta. In: SILVA, F.C. (Org.). Sustentabilidade e vulnerabilidade na Amazônia brasileira. Belém, NAEA, 2014a.

FIGUEIREDO, L. de; et al. As novas teorias do crescimento econômico - contribuição para a política regional. In: Diretrizes para Formulação de Políticas de Desenvolvimento Regional e de Ordenação do Território Brasileiro. FACE/ CEDEPLAR-UFMG. Ministério da Integração. Belo Horizonte, Fev., 2004.

IBGE (Instituto Brasileiro de Geografia e Estatística). Sistema IBGE Cidades. Disponível em: http://www.cidades.ibge.gov.br/xtras/home.php. Acesso em 07 de abril de 2016.

IBGE (Instituto Brasileiro de Geografia e Estatística). Produção Agrícola Municipal. Disponível em: http://www.sidra.ibge.gov.br/. Acesso em 11 de abril de 2016.

ISA- (Instituto Socioambiental) O Xingu na mira da Soja, 2003, Disponível em http://www. socioambiental.org/esp/soja/1.shtm Acesso em: 20 de março de 2016.

LIMA, M. B. et all. Panorama Da Economia Mato-Grossense - 2006. Equipe Econômica da Superintendência de Estudos e Informações SEI. SEPLAN-MT, 2008.

MARCONI, M. de A.; LAKATOS, E. M. Metodologia do trabalho científico. $6^{a}$. Ed., São Paulo: Atlas, 2006. MIN - Ministério da Integração Nacional. Política Nacional de Desenvolvimento Regional (PNDR), 2009.

MELO, J. S. Qual é o determinante da expansão da fronteira agrícola matogrossense no período 2001/2007: produção agrícola ou pecuária? Dissertação (Mestrado). Universidade Federal de Mato Grosso - UFMT, Cuiabá, 2009.

NASCIMENTO, Luis Felipe. LEMOS, Â. D. C.; MELLO, Maria Celina Abreu de. Gestão Socioambiental Estratégica. Porto Alegre: Bookman, 2008. v. 1. 232 p.

OLIVEIRA, A. M., et al. Elementos Condicionantes Da Evolução Socioeconômica De Mato Grosso E Da Mesorregião Norte Matogrossense. Revista de Estudos Sociais - Ano 2011, No. 25, Vol. 13 p.52-70. 
PINTO, M. O. Entre o sonho e a realidade: desafios da política ambiental na Amazônia. 170 p. Dissertação (Mestrado). Universidade de Brasília. Centro de Desenvolvimento Sustentável, Brasília, 2006.

RIBEIRO, A. L. Modelo de indicadores para mensuração do desenvolvimento sustentável na Amazônia. Tese (Doutorado) Ciências Desenvolvimento Socioambiental. NAEA/PA, Belém, 2002.

RIBEIRO. A. R.. A colonização promovida por empresas e famílias do Centro-Sul na Amazônia mato-grossense. Tese (Doutorado). Universidade Federal do Pará, Belém, 2013.

ROMEIRO, Ademar Ribeiro. Economia ou Economia Política da Sustentabilidade. In MAY, Peter H. et al orgs.). Economia do Meio Ambiente, Rio de Janeiro, Campus, 2001.

SACHS, I. (2008). Desenvolvimento: Includente, Sustentável, Sustentado. Rio de Janeiro: Garamond (152 p.).

SACHS, I. Espaços, tempos e estratégias de desenvolvimento. São Paulo: Vértice, 1986.

SCATOLIN, F. D. Indicadores de Desenvolvimento: um sistema para o Estado do Paraná. Dissertação (Mestrado em Economia) - Universidade Federal do rio Grande do Sul, Porto Alegre, 1989.

SEDTUR. Secretaria de Estado de Desenvolvimento do Turismo - Disponivel em http://www.sedtur.mt.gov.br/Araguaia acesso em 19 de março de 2016.

SEPLAN-MT. Secretaria de Planejamento do Estado de Mato Grosso - Anuário 2007. Disponível em: http://www.zsee.seplan.mt.gov.br/anuario2007/index.html

SILVA, J. A. Direito Ambiental Constitucional. São Paulo: Malheiros, 1995.

SILVA, L. K. R. Migração dos trabalhadores gaúchos para a Amazônia Legal (19701985). Klepsidra: Revista virtual de história, $N^{\circ} .23,2005$.

SIQUEIRA, E. M. O processo histórico de Mato Grosso. 2. ed. Cuiabá: UFMT, 1990.

TAFNER JR., A. W. EXPANSÃO DA FRONTEIRA AGROPECUÁRIA DO OESTE PAULISTA PARA A AMAZÔNIA: A Trajetória das Famílias Ometto e Da Riva e a Colonização do Norte Mato-grossense. Tese (Doutorado). Universidade Federal do Pará, Belém, 2015.

VEIGA, José Eli da, Desenvolvimento sustentável: o desafio do século XXI / Rio de Janeiro: Garamond, $20103^{\circ}$ ed.

VILLAR, P. M. Del. et all. Impacto do projeto de asfaltamento da BR-163: perspectivas da sociedade e do setor produtivo agrícola ao longo do eixo da Cuiabá - Santarém. Brasília DF, 2005. 